\title{
Temperature Simulation and Heat Exchange in a Batch Reactor Using Ansys Fluent
}

\author{
Rahul Kooragayala
}

Follow this and additional works at: https://researchrepository.wvu.edu/etd

\section{Recommended Citation}

Kooragayala, Rahul, "Temperature Simulation and Heat Exchange in a Batch Reactor Using Ansys Fluent" (2018). Graduate Theses, Dissertations, and Problem Reports. 6006.

https://researchrepository.wvu.edu/etd/6006

This Thesis is protected by copyright and/or related rights. It has been brought to you by the The Research Repository @ WVU with permission from the rights-holder(s). You are free to use this Thesis in any way that is permitted by the copyright and related rights legislation that applies to your use. For other uses you must obtain permission from the rights-holder(s) directly, unless additional rights are indicated by a Creative Commons license in the record and/ or on the work itself. This Thesis has been accepted for inclusion in WVU Graduate Theses, Dissertations, and Problem Reports collection by an authorized administrator of The Research Repository @ WVU. For more information, please contact researchrepository@mail.wvu.edu. 


\title{
Temperature simulation and heat exchange in a batch reactor using Ansys Fluent
}

\section{Rahul Kooragayala}

\author{
Thesis submitted to the \\ Benjamin M. Statler College of Engineering and Mineral Resources at \\ West Virginia University
}
in partial fulfillment of the requirements for the degree of
Master of Science
in
Mechanical Engineering

Cosmin Dumitrescu, Ph.D., Chair

Hailin Li, Ph.D.

Vyacheslav Akkerman, Ph.D.

Department of Mechanical and Aerospace Engineering

\author{
Morgantown, West Virginia \\ 2018
}

Keywords: Ansys Fluent, batch reactor, heat transfer, simulation, water vaporization

Copyright 2018 Rahul Kooragayala 


\section{Abstract \\ Temperature simulation and heat exchange in a batch reactor using Ansys Fluent Rahul Kooragayala}

Internal combustion (IC) engines are the main power source for on-road and off-road vehicles. Natural gas $(\mathrm{NG})$ is a cleaner alternative for conventional petroleum-based fuels. A solution to avoid some of the issues associated with a gaseous fuel is to convert the methane in NG to a liquid fuel such as methanol. This thesis is part of a larger experimental and simulation effort at West Virginia University dedicated to the development of a direct methane-to-methanol conversion technology based on an innovative homogeneous catalysis and a novel reactor design. The goal was to support the experimental effort by using the simulation to design the strategies for heat addition and rejection in the reactor that would optimize the methane-to-methanol conversion rate while protecting the catalyst. The simulation was created in ANSYS® Academic Research Mechanical, Release 17.2, Fluent, using several assumptions regarding the working fluids properties or heat transfer. The study found that while the simulation can predict the phase change inside the reactor, it did not conserve reactor mass. This suggests that the default volume of fluid approach was not capable of heat and mass transfer through the phase interface. A user-defined function (UDF) is probably needed to solve this issue. The results also show that an optimum heater design would use both sides and bottom heaters, which would result in a more uniform heat input. Specifically, it was suggested to use three different heating units placed around the lateral walls of the reactor, with individual heat controls. This way, the heat flux to the reactor and interior reactor temperature can be properly controlled. An additional cooling coil can be incorporated to remove the heat produced during the synthesis process. 


\section{Dedication}

This thesis is dedicated to the memory of my beloved father, Ram Murthy Kooragayala, who always believed in my ability to be successful in the academic arena 


\section{Acknowledgements}

Foremost, I would like to express my sincere gratitude to my advisor, Dr. Cosmin Dumitrescu, for his continuous support, patience, motivation, enthusiasm, and immense knowledge. His guidance helped me during my research and writing this thesis. I want to also thank him for accepting me in his research group and funding me for two semesters.

Besides my advisor, I want to thank the rest of my thesis committee, Dr. Hailin Li and Dr. Vyacheslav Akkerman, for their encouragement and insightful comments. I thank my fellow research colleagues in the Advanced Combustion Laboratory, Ali Sivri, Jinlong Liu, Sarah Mills, and Rasik Pondicherry, and all my friends at Morgantown.

A special thank you to Sai Satish Guda, a PhD. graduate at WVU, who spent a lot of time and effort to discuss with me about meshing and the CFD software, during the beginning of my project. Thanks are not sufficient for all the help he offered me.

Lastly, I would like to thank all my friends and my family, especially my mother, Nagamani Kooragayala, who has always been ready to support me. Her love and sacrifice have made this possible for me. 


\section{Content}

1. Introduction 1

1.1. Natural gas and methanol $\quad 1$

1.2. Thesis objectives $\quad 2$

1.3. Project challenges $\quad 3$

1.4. Literature review 4

1.4.1.Batch reactor $\quad 4$

1.4.2. Solutions for heating and/or cooling reactor content 5

1.4.3.Heating/cooling jacket solutions

1.5. Simulation theory $\quad 6$

1.5.1.Multiphase flow 6

1.5.2.Modeling approaches 6

1.5.3.The Euler-Euler approach and VOF modeling 6

1.6. The finite volume method 9

1.7. Coupled and segregated solvers 10

2. Methodology 10

2.1. Experimental setup 10

2.1.1.Methanol synthesis $\quad 10$

2.1.2. Water vaporization rate 12

2.2. CFD software 14

2.3. Model geometry and mesh generation 14

2.3.1.Model description and properties of constituents 14

2.3.2. Water evaporation model 17

2.3.3. $\mathrm{SO}_{3}$ liquid-to-vapor phase change $\quad 20$

2.3.4.Heating-mantel-to-the-reactor-content heat transfer model 20

2.4. Simulation settings 22

2.5. Boundary conditions 23

2.6. Model convergence criteria 23

2.7. Simulation evaluation criteria $\quad 23$

3. Results and discussions 24

4. Conclusions and future work 37

References $\quad 39$

$\begin{array}{ll}\text { Appendix } & 42\end{array}$ 


\section{List of figures}

Figure 1. Homogeneous catalysis for methane-to-methanol synthesis 11

Figure 2. Schematic of the methane-to-methanol synthesis

Figure 3. Water vaporization rate experimental setup. The heating jacket is shown in the bottom right figure $\quad 13$

Figure 4. 2-D cross section of the reactor with paddle 15

Figure 5. Reactor used for methane-to-methanol synthesis 16

Figure 6. Reactor heating mantle 16

Figure 7. Schematic of the water evaporation model $\quad 18$

Figure 8. Geometry of water evaporation model 18

Figure 9. Schematic of $\mathrm{SO}_{3}$ evaporation model 20

Figure 10. Schematic of heat transfer via mantel 21

Figure 11. Geometry of the reactor without mixing paddle 21

Figure 12. Mesh for the reactor with mixing paddle 22

Figure 13. Reactor-content temperature change with time during the water vaporization experiment

Figure 14. Liquid water volume fraction $\quad 27$

Figure 15. Effect of timestep on liquid vaporization 28

Figure 16. Mass of liquid and vapor inside the reactor (0.001 s timestep) 29

Figure 17. $\mathrm{SO}_{3}$ liquid volume fraction (no surface tension; $0.0001 \mathrm{~s}$ timestep) 31

Figure 18. Effect of surface tension on mass of vapor 32

Figure 19. Effect of surface tension on liquid vaporization 32

Figure 20. Liquid $\mathrm{SO}_{3}$ volume fraction $(0.001 \mathrm{~N} / \mathrm{m}$ surface tension) 33

Figure 21. Temperature profile at various points in the reactor 34

Figure 22. Inside reactor temperature function of time 35

Figure 23. Reactor model with stirrer. Top - the Solidworks model. Bottom: simulation at $\mathrm{t}=0.1 \mathrm{~s}$

and at $\mathrm{t}=0.8 \mathrm{~s}$, for a stirrer speed of $500 \mathrm{rpm}$ 


\section{List of Tables}

Table 1. Reactor dimensions 17

Table 2. Reactant properties 17

Table 3. Mesh properties for water and sulfur trioxide vaporization models 19

Table 4. Mesh properties for reactor heating model 19

Table 5. Simulation settings 22

Table 6. Comparison of properties used for experiment and simulation 26

Table 7. Comparison of mass of liquid and vapor with different time step values 27

Table 8. Predicted water liquid and vapor mass after $30 \mathrm{~s} \quad 28$

Table 9. Predicted $\mathrm{SO}_{3}$ liquid and vapor mass after $3 \mathrm{~s} \quad 30$ 


\section{Abbreviations}

$\mathrm{NG}$ - Natural gas

H/C - Hydrogen / Carbon

$\mathrm{CO}_{2}$ - Carbon dioxide

$\mathrm{CH}_{4}$ - Methane

$\mathrm{CH}_{3} \mathrm{OH}-$ Methanol

$\mathrm{CH}_{3} \mathrm{OSO}_{3} \mathrm{H}-$ Methyl bisulfate

LNG - Liquified natural gas

SI - Spark ignition

$\mathrm{SO}_{2}-$ Sulfur dioxide

$\mathrm{SO}_{3}-$ Sulfur trioxide

$\mathrm{H}_{2} \mathrm{SO}_{4}$ - Sulfuric acid

VOF - Volume of fluid

UDF - User defined function

FVM - Finite volume method 


\section{Chapter 1. Introduction}

\subsection{Natural gas and methanol}

Internal combustion (IC) engines are the main power source for on-road and off-road vehicles. While there is an increased interest in vehicle hybridization and electrification, forecasts predict that gaseous and liquid fuels will still provide most of the energy used in the transportation sector in U.S. Nevertheless, the adverse effects of IC engine emissions on human health and environment and the dependence on oil imports will probably result in much stringent future emission regulations. As a result, there is an increased interest on finding cleaner alternatives for conventional petroleum-based fuels. Natural gas (NG) is such an alternative, due to its increased availability, lower cost, and compatibility with both spark ignition (SI) and compression ignition (CI) engines $[1,2]$. In addition, NG's higher hydrogen-to-carbon $(\mathrm{H} / \mathrm{C})$ ratio lowers engine-out $\mathrm{CO}_{2}$ emissions compared to gasoline or diesel. However, NG lowers engine's volumetric efficiency as it displaces a large fraction of air in the intake compared to a liquid fuel. While the use of liquefied NG (LNG) can solve this issue, LNG requires complex injection systems. Furthermore, LNG has vehicle storage issues [3]. A solution is to convert the methane $\left(\mathrm{CH}_{4}\right)$ in $\mathrm{NG}$ to a liquid fuel such as methanol $\left(\mathrm{CH}_{3} \mathrm{OH}\right)$, which is an alcohol-based fuel that can run even cleaner than NG [4]. Compared to methane, methanol engines can run at delayed spark timing due to its higher flame speed, which lowers the combustion temperature and reduce $\mathrm{NO}_{\mathrm{x}}$ emissions [4]. This thesis is a part of a larger experimental and simulation effort at West Virginia University dedicated to the development of a direct methane-to-methanol conversion technology based on an innovative homogeneous catalysis and a novel reactor design. Equations 1.1 to 1.4 shows the main chemical reactions involved in the methane-to-methanol conversion and the heat of reaction (in $\mathrm{kJ} / \mathrm{mol}$ ) associated to each step.

$$
\begin{array}{cr}
\mathrm{CH}_{4}+\mathrm{SO}_{3}+\mathrm{H}_{2} \mathrm{SO}_{4} \rightleftarrows \mathrm{CH}_{3} \mathrm{OSO}_{3} \mathrm{H}+\mathrm{SO}_{2}+\mathrm{H}_{2} \mathrm{O} & \Delta \mathrm{H}=116 \mathrm{KJ} / \mathrm{mol} \\
\mathrm{CH}_{3} \mathrm{OSO}_{3} \mathrm{H}+\mathrm{H}_{2} \mathrm{O} \rightleftarrows \mathrm{CH}_{3} \mathrm{OH}+\mathrm{H}_{2} \mathrm{SO}_{4} & \Delta H=-181 \mathrm{KJ} / \mathrm{mol} \\
\mathrm{SO}_{2}+0.5 \mathrm{O}_{2} \rightleftarrows \mathrm{SO}_{3} & \Delta H=-98 \mathrm{KJ} / \mathrm{mol}
\end{array}
$$

with the global conversion equation being:

$$
\mathrm{CH}_{4}+\mathrm{H}_{2} \mathrm{SO}_{4} \rightleftarrows \mathrm{CH}_{3} \mathrm{OH}+\mathrm{SO}_{2}
$$


The methanol generation process discussed in this work used a mixture of oleum (70 vol\% $\mathrm{H}_{2} \mathrm{SO}_{4}, 30 \mathrm{vol} \% \mathrm{SO}_{3}$ ) and methane. Oleum (or fuming sulfuric acid) is a solution of different compositions of sulfur trioxide in sulfuric acid. Oleum is produced in the contact process, where sulfur is oxidized to sulfur trioxide and subsequently dissolved in concentrated sulfuric acid. Sulfuric acid is regenerated by dilution of part of the oleum. Oleum is a useful form for transporting sulfuric acid compounds, typically in rail tank cars, between oil refineries and industrial consumers. Oleum is an important intermediate in the manufacture of sulfuric acid due to its high enthalpy of hydration [5]. $\mathrm{SO}_{3}$ when added to concentrated sulfuric acid dissolves readily, forming oleum which can be diluted with water to produce additional sulfuric acid. Oleum is a harsh reagent and is highly corrosive. Oleum is used in the manufacture of many explosives [6].

Oleum and methane (i.e., the working fluids) were pressurized in a 50-ml reactor over a platinum-bipyrimidine-based catalyst [7,8]. Specifically, the stainless-steel reactor was filled with $15 \mathrm{ml}$ of oleum and 50-70 mg of a catalyst. The reactor was then filled up with $\mathrm{CH}_{4}$ at a pressure of $40 \mathrm{bar}$, then heated for 2.5 hours at $488 \mathrm{~K}$ using an external heating jacket. A stirrer placed inside the reactor ensured the mixing between the working fluids throughout the conversion process. After some time during the mixture heating, exothermic reactions between methyl bisulfate $\left(\mathrm{CH}_{3} \mathrm{OSO}_{3} \mathrm{H}\right)$ and water $\left(\mathrm{H}_{2} \mathrm{O}\right)$ as well as between sulfur dioxide $\left(\mathrm{SO}_{2}\right)$ and oxygen $\left(\mathrm{O}_{2}\right)$ were initiated (see Eqs. (1.2) and (1.3)). The heat release increases the temperature of the reactor substantially and must be rejected for high conversion efficiency and catalyst protection. If the reactor temperature is not controlled (i.e., the reaction rates are not controlled), the catalyst will be consumed completely, which is against the design requirements of maintaining $90 \%$ of the original catalyst at the end of conversion. Methanol is synthesized when the temperature inside the reactor is within the range of optimum catalyst operation. This means that both the reactor temperature and inside reaction rates need to be monitored throughout the conversion process. To get an estimate of how much heat is generated and the temperature at different parts of the reactor, this study investigated the reactor heating and the heat generated once the conversion process was initiated.

\subsection{Thesis objectives}

This thesis used the experimental setup of the larger project of methane-to-methanol conversion as a starting point to develop a model that simulated the thermal conditions inside the reactor. The goal was to support the experimental effort by using the simulation to design the 
strategies for heat addition and rejection in the reactor that would optimize the methane-tomethanol conversion rate while protecting the catalyst. The simulation was created in ANSYS® Academic Research Mechanical, Release 17.2, Fluent, using several assumptions regarding the working fluids properties or heat transfer.

The main objectives of this study were:

- Determine the time it needs to raise the temperature of the reactor contents to $488 \mathrm{~K}$

- Model a heat exchanger that would add the heat required by the endothermic reaction

- Compare different types of heat exchangers that can be used to optimize the methane to-methanol conversion.

\subsection{Project challenges}

Several challenges were identified. Specifically,

- Oleum is a reactant in Eq. (1.1). The author could not find any data in the literature on the physical properties for the oleum used in the experiment. As a result, the properties of oleum were based on averaging the properties of the oleum components (i.e., $\mathrm{H}_{2} \mathrm{SO}_{4}$ and $\left.\mathrm{SO}_{3}\right)$.

- Methyl bisulfate, which is formed after the first step, is a reactant in the second step, Eq. 1.2. Methyl bisulfate is hydrolyzed to form sulfuric acid. The properties of the individual species, the reaction rate, and the amount of catalyst retention which contributes to the porous material inside the reactor are essential to properly simulate the endothermic reaction. Without correct properties, the simulation results can differ when compared to the experiment.

- The batch reactor dimensions were provided by the manufacturer. The model was used based on engineering approximations due to difficulties in meshing complex geometries, the lack of complete dimensions of the reactor, material differences, and a lack of correct fluid properties. 


\subsection{Literature Review}

Multicomponent mixing is a very complex phenomenon, especially when one or more fluids change their phases due to changes in pressure and/or temperature. Even small changes in fluid properties inside a chemical reactor can affect the reaction of interest in terms of conversion rate, loss of catalyst, or formation of undesirable residuals. Also, since a change in pressure generally results in a thermal gradient inside the reactor, a dangerous situation like reactor failure may occur if reactor temperature is not well controlled. As a result, most reactors rely on proper control of temperature, which is usually employed using heat exchangers.

For uniform heat transfer, we need to maintain a homogenous mixture inside the reactor. To achieve this objective, a stirrer or paddle is mounted inside the reactor. The paddle is in continuous motion throughout the conversion process. Proper mixing is important for reducing investment and operating costs, providing high yields when mass transfer is limiting, and thus enhancing process effectiveness [9]. The mixing process uses mechanical or chemical methods that are taking place under either laminar or turbulent flow conditions and it is correlated with the stirrer Reynolds number $(R e)$. Optimum mixing $R e$ gives a high rate of reaction [10].

Compared to industrial reactors, laboratory reactors allow better control over chemical reactions, including the temperature control of the vessel content and measurement of process parameters such as pressure, mixing, and dispersing applications [11]. Nevertheless, the heat addition to and/ or heat rejection from the reactor are very complex, especially when the vessel content is non-homogenous and multi-phased. Furthermore, non-uniform heat transfer to the reactor interior is expected for reactors with asymmetrical walls such as the reactor used in this investigation.

\subsubsection{Batch reactor}

A batch reactor consists of a tank with an agitator and a heating or cooling system. They are usually fabricated from steel, stainless steel, or glass-lined steel. Liquids and solids are usually charged via connections in the top cover of the reactor. Vapors and gases usually discharge through the top, too. A paddle is used for stirring the reactor content and intended to produce a uniform mixing motion at velocities that do not increase the temperature inside the reactor. The main advantage of a batch reactor is its versatility. A single vessel can carry out a series of operations 
without the need to break the containment, which is particularly useful when processing toxic compounds.

\subsubsection{Solutions for heating and/or cooling reactor content}

Products inside batch reactors generally release or absorb heat during the process. To maintain the reactor content at the required temperature, heat must be added to or removed from the reactor. As a result, heating and/or cooling coils or jackets are employed for heating and/or cooling batch reactors [12]. In the case of heating/cooling jackets, the working fluid passing through jacket adds or removes heat to/from the reactor walls. Three parameters define the performance of a heating/cooling jacket [12]:

1. The response time needed to modify the jacket temperature

2. The uniformity of jacket temperature

3. The stability of jacket temperature

\subsubsection{Heating/cooling jackets solutions}

\section{Single external jacket}

The simplest design consists of a single jacket surrounding the vessel. The working fluid is injected inside the jacket passages at high velocities using nozzles and flows around and the vessel. The temperature inside the jacket is regulated to control heating or cooling. However, it can take a long period of time to modify the temperature of the working fluid inside the jacket, particularly for large reactor applications. This can result in a sluggish temperature control. As a result, the heat transfer distribution may not be ideal, and heating or cooling may vary between the side walls and the bottom [12].

\section{Batch reactor with half-coil jacket}

Another solution is a half-coil jacket, which is made by welding a half pipe to create a semicircular flow around the outer surface of the vessel. The fluid passes through the channel in a plug flow manner. Many coils may be used to deliver heat transfer fluid. Similar to a single jacket, the temperature is regulated to heat or cool the reactor. The plug flow characteristics permits faster displacement of the working fluid inside the jacket. This is essential for better temperature control. More, this design provides good heat transfer distribution avoids non-uniform heating or cooling between the side walls and the bottom [12]. 


\section{Batch reactor with constant flux (co-flux) jacket}

The constant flux cooling jacket is not a single jacket but a series of 20 or more small jacket elements. There is a temperature control valve, which operates by opening and closing these channels as required. Heat transfer area can hence be varied in this way and the temperature can be regulated without changing the jacket temperature. The temperature control response is very fast due to the short length of the channels and the high velocity of the working fluid. Heating or cooling flux is uniform because the jacket operates at a constant temperature. However, the oscillations of temperature seen in other jackets are absent. The process heat can also be measured very precisely [12].

\subsection{Simulation theory}

The continuity and the momentum equations (Eqns. 1.5 and 1.6) describe the state of any type of flow and are generally solved for all flows in CFD modelling, [13]

$$
\begin{gathered}
\frac{\partial \rho}{\partial t}+\nabla(\rho \boldsymbol{u})=0 \\
\frac{\partial \rho \boldsymbol{u}}{\partial t}+\nabla(\rho \boldsymbol{u} \boldsymbol{u})=-\nabla \boldsymbol{p}+\nabla \boldsymbol{\tau}+\rho \boldsymbol{g}
\end{gathered}
$$

where $\rho$ is density, $\boldsymbol{u}$ is the flow instantaneous velocity, $\boldsymbol{p}$ is pressure, $\boldsymbol{\tau}$ is the viscous stress tensor, and $\boldsymbol{g}$ is the gravity vector.

\subsubsection{Multiphase flow}

A multicomponent fluid in Ansys ${ }^{\circledR}$ Fluent consists of a mixture of chemical species that are mixed at the molecular level. In this case, a single mean velocity and temperature field are solved for the fluid.

Fluids in a multiphase flow are mixed at macroscopic length scales. Hence it is necessary to solve for different characteristics such as velocity and temperature field for each fluid. These may interact with each other by means of interfacial forces and heat and mass transfer across the phase interfaces. 


\subsubsection{The Euler-Euler approach and VOF modeling}

Ansys ${ }^{\circledR}$ Fluent allows multiple modelling approaches. The modelling approach used in this study, the Euler-Euler approach, is discussed next.

All phases are treated as continuous in Euler-Euler models. Multi-fluid models are appropriate for separate flows where both phases can be described as a continuum. The dispersed phase equations are averaged in each cell to achieve mean fields. For a dispersed phase to be described as a continuum, the volume fraction should be high.

Phases are treated separately, and a set of conservation equations is solved for every phase. Coupling between the phases is achieved through a shared pressure and interphase exchange coefficients. In addition to the regular transport equations, a transport equation for the volume fraction is also solved for each phase. The governing equations for a two-fluid model with two continuous phases are shown below.

$$
\begin{gathered}
\frac{\partial \alpha_{k} \rho_{k}}{\partial t}+\nabla \cdot\left(\alpha_{k} \rho_{k} \mathbf{U}_{k}\right)=0 \\
\frac{\partial \alpha_{k} \rho_{k} \mathbf{U}_{k}}{\partial t}+\nabla \cdot\left(\alpha_{k} \rho_{k} \mathbf{U}_{k} \mathbf{U}_{k}\right)=-\alpha_{k} \nabla \mathbf{P}+\alpha_{k} \nabla \cdot \boldsymbol{\tau} k+\alpha_{k} \rho_{k} \mathbf{g}_{k}+\mathbf{S}_{\mathrm{k}}=0 \\
\frac{\partial \alpha_{k}}{\partial t}+\nabla \cdot\left(\alpha_{k} \mathbf{U}_{k}\right)=0
\end{gathered}
$$

where $\boldsymbol{U}$ is the mean velocity field and $\boldsymbol{P}$ is the mean pressure shared by the phases. The subscript $k$ refers to the $k^{\text {th }}$ continuous phase.

The volume of fluid (VOF) model, which is one of the multiphase models under this type of approach, is used for the current simulations. The VOF model can be used for two or more immiscible fluids where the interface between the fluids is of interest. In the VOF model, the fluids share a single set of momentum equations and the volume fraction of each fluid in each cell is tracked in the domain. A variable is introduced for each additional phase that we add to the model, which is the volume fraction of the phase in the computational cell. The volume fractions of all phases sum to unity in each control volume.

The fields for all variables and properties are shared by the phases and represent volumeaveraged values, as long as the volume fraction of each of the phases is known at each location. If the $q^{\text {th }}$ fluid's volume fraction in the cell is denoted as $\alpha_{q}$ then the following three conditions are possible: 
$\alpha_{q}=0$ : The cell is empty (of the $q^{\text {th }}$ fluid).

$\alpha_{q}=1$ : The cell is full (of the $q^{\text {th }}$ fluid).

$\alpha_{q}<1$ : The cell contains the interface between the $q^{\text {th }}$ fluid and one or more other fluids.

The appropriate properties and variables will be assigned to each control volume within the domain based on the value of $\alpha_{q}$.

The properties in the transport equations are determined by the presence of component phases in each control volume. In a two-phase system, if the phases are represented by the subscripts 1 and 2 , and if the volume fraction of the second of these is being tracked, the density in each cell is given by:

$$
\rho=\alpha_{2} \rho_{2}+\left(1-\alpha_{2}\right) \rho_{1}
$$

In general, for an $n$-phase system, the volume-fraction-averaged density takes on the following form:

$$
\rho=\sum \alpha_{2} \rho_{2}
$$

All other properties (e.g., viscosity) are computed in this manner.

The transport equations are solved for mixture properties without slip velocity, meaning that all field variables are assumed to be shared between the phases. To track the interface, an advection equation for the indicator function is solved. To obtain a sharp interface, the discretization of the indicator function equation is crucial. Different techniques have been proposed for this. The equations solved in the VOF method are shown below.

$$
\begin{gathered}
\frac{\partial \rho_{m}}{\partial t}+\nabla \cdot(\rho m \mathbf{u})=0 \\
\frac{\partial \rho_{m} \mathbf{u}}{\partial t}+\nabla \cdot(\rho m \mathbf{u} \mathbf{u})=-\nabla \mathrm{P}+\nabla \cdot \boldsymbol{\tau}+\rho m \mathbf{g}+\mathbf{S}=0 \\
\frac{\partial \alpha}{\partial t}+\nabla \cdot(\alpha \mathbf{u})=0
\end{gathered}
$$

where $\rho_{m}=\sum \alpha_{k} \rho_{k}$. The subscript $m$ refers to mixture properties.

The VOF method [14-16] has an integral mass conservation property, capturing interface with heat transfer of phase change [17]. When solving phase-change problems, the characteristic of mass conservation is important [18]. Ansys ${ }^{\circledR}$ Fluent employs the VOF method to solve two-phase flows. But, the default VOF method cannot simulate heat and mass transfer through the phase interface. To overcome this, the phase-change model is added to the source terms in the governing 
equations using user-defined functions (UDFs). The use of empirical expressions to quantify the interfacial heat and mass transfer is a common way to model phase change phenomena [19, 20]. The approach is important for simple geometries and limited for any other geometry [21].

The phase-change model proposed by Lee [22] has been most widely used. The mass transfers are given by the following equations. Equations 1.15 and 1.16 are for evaporation and condensation, respectively.

$$
\begin{array}{cc}
\dot{m}_{v}=-\dot{m}_{l}=r \alpha_{l} \rho_{l} \frac{T-T_{\text {sat }}}{T_{\text {sat }}} & T>T_{\text {sat }} \\
\dot{m}_{l}=-\dot{m}_{v}=r \alpha_{l} \rho_{l} \frac{T_{\text {sat-T }}}{T_{\text {sat }}} & T<T_{\text {sat }}
\end{array}
$$

where $r$ denotes the mass transfer intensity factor with unit $\mathrm{s}^{-1}$. The value of $r$ is recommended to be such as to maintain the interfacial temperature reasonably close to the saturation temperature, and to avoid divergence. In the numerical studies of $\mathrm{Wu}$ et al. [23], $r$ was set as $0.1 \mathrm{~s}^{-1}$ to numerically maintain the interface temperature close to the saturation temperature.

\subsection{The finite volume method}

The governing flow equations presented in this section are non-linear partial differential equations which can be solved analytically for only simple cases, else, we solve them numerically. One of the methods for discretizing transport equations in CFD codes is the finite volume method (FVM) FVM method divides the computational domain in control volumes and conservation principles are applied to each control volume. This ensures conservation, both in each cell and globally in the domain, which is a great advantage of the FVM as it allows for the use of unstructured grids, which decreases the computational time. Two versions of the FVM are presented in below.

\section{Centre node based FVM}

The computational domain is divided into a mesh where each element in the mesh makes up a control volume in a center node based FVM. Over each control volume, the transport equations are integrated and then discretized to obtain one set of algebraic equations for each control volume. The value of each variable is stored in a node in the center of the cell. 


\section{Vertex based FVM}

In this method, control volumes are constructed around each mesh vertex. The governing equations are integrated over each control volume, the discretization is done within each element and properties are applied to the control volume. Properties are needed to solve the discretized equations for other locations than the mesh vertices.

\subsection{Coupled and segregated solvers}

In discretized form of the governing equations pressure and velocity are strongly coupled. Obtaining pressure field is not simple. Momentum equations can be used to solve for velocities if the pressure is known but the continuity equation cannot be used directly to obtain the pressure field. The fact that the pressure and velocity fields are coupled is an issue that needs to be dealt with in compressible CFD codes. Two main types of solvers exist for handling the pressurevelocity coupling: segregated solvers and coupled solvers.

A segregated solver uses a pressure correction equation. The momentum equations are solved first, using a pressure. A pressure correction equation is solved to update the pressure field and then the velocity field is also updated. This is repeated until the obtained velocity field satisfy both the momentum equations and the continuity equation. The SIMPLE (semi implicit method for pressure linked equations) scheme is generally used. Only one discrete equation needs to be stored at a time, hence lower memory is required [24].

In a coupled solver, the momentum and continuity equations are solved simultaneously. As the discrete system of all equations needs to be stored at the same time the memory requirement is higher for a coupled solver and it takes more time to complete one iteration. The total number of iterations to achieve convergence is usually lowered when using a coupled solver, for taking more time for each iteration [25]. 


\section{Chapter 2. Methodology}

This section presents the simulation methodology. The selection of the computational geometry and mesh generation are discussed first. The choice of simulation settings and the description of the boundary conditions follows. Finally, the numerical convergence and evaluation criteria are presented.

\subsection{Experimental Setup}

\subsubsection{Methanol synthesis}

A typical homogeneous catalyst system and reaction pathways for methane conversion to methanol are shown in Figure 1. Several catalysts were evaluated for their selective oxidation of methane to methanol and developed further for improved efficiency and stability. The homogeneous catalyst is immobilized and integrated into a novel reactor design as illustrated in Figure 2. The experiment objective was to immobilize a selected homogeneous catalyst on substrates that allow for the highly selective homogeneous catalysis to occur under heterogeneous conditions that can be extended or incorporated into new reactor designs. The stability of each immobilized catalyst system was evaluated by measuring the yield, selectivity, and rate of methane conversion to methanol.

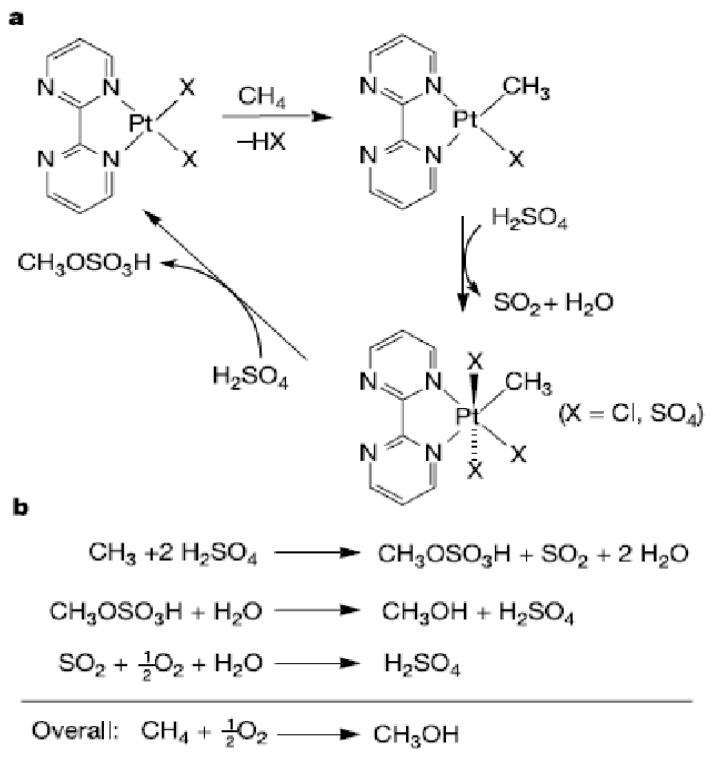

Figure 1. Homogeneous catalysis for methane-to-methanol synthesis 


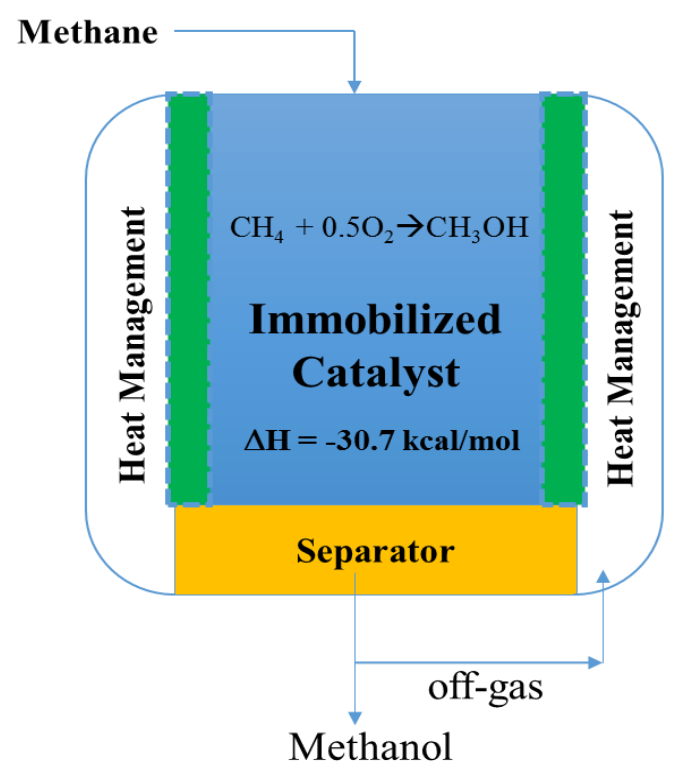

Figure 2. Schematic of the methane-to-methanol synthesis

Temperature control is crucial to avoid temperature run-away situations that could be detrimental to catalyst life and selectivity. The heat exchanger design can be optimized using several heat exchanger technologies such as shell-and tube or tube-in-tube CFD and heat transfer simulations.

\subsubsection{Water vaporization rate}

A water vaporization experiment was performed to estimate the heating parameters used in the CFD simulation. The reason was that water properties are well defined at the temperature and pressure conditions in this investigation. In this experiment, the same reactor used for methanol synthesis was filled with $25 \mathrm{ml}$ of water. After the reactor was sealed, it was placed inside the heating jacket. Figure 3 shows the experimental setup, including the heating jacket with and without the reactor mounted inside it. The initial pressure and temperature of the water inside the reactor were 101,325 $\mathrm{Pa}$ and $294 \mathrm{~K}$, respectively. The heat flux applied to the reactor side walls was estimated based on the heating jacket specifications. The rate of water vaporization was determined by measuring the reactor-content temperature with respect to time. While the pressure inside the reactor will slightly increase throughout the heating process, it was expected that the measured temperature would follow the well-known phase change T-V diagram at a constant 
pressure. An increase in reactor-content temperature above the saturation temperature at 101,325 Pa would indicate complete water vaporization.

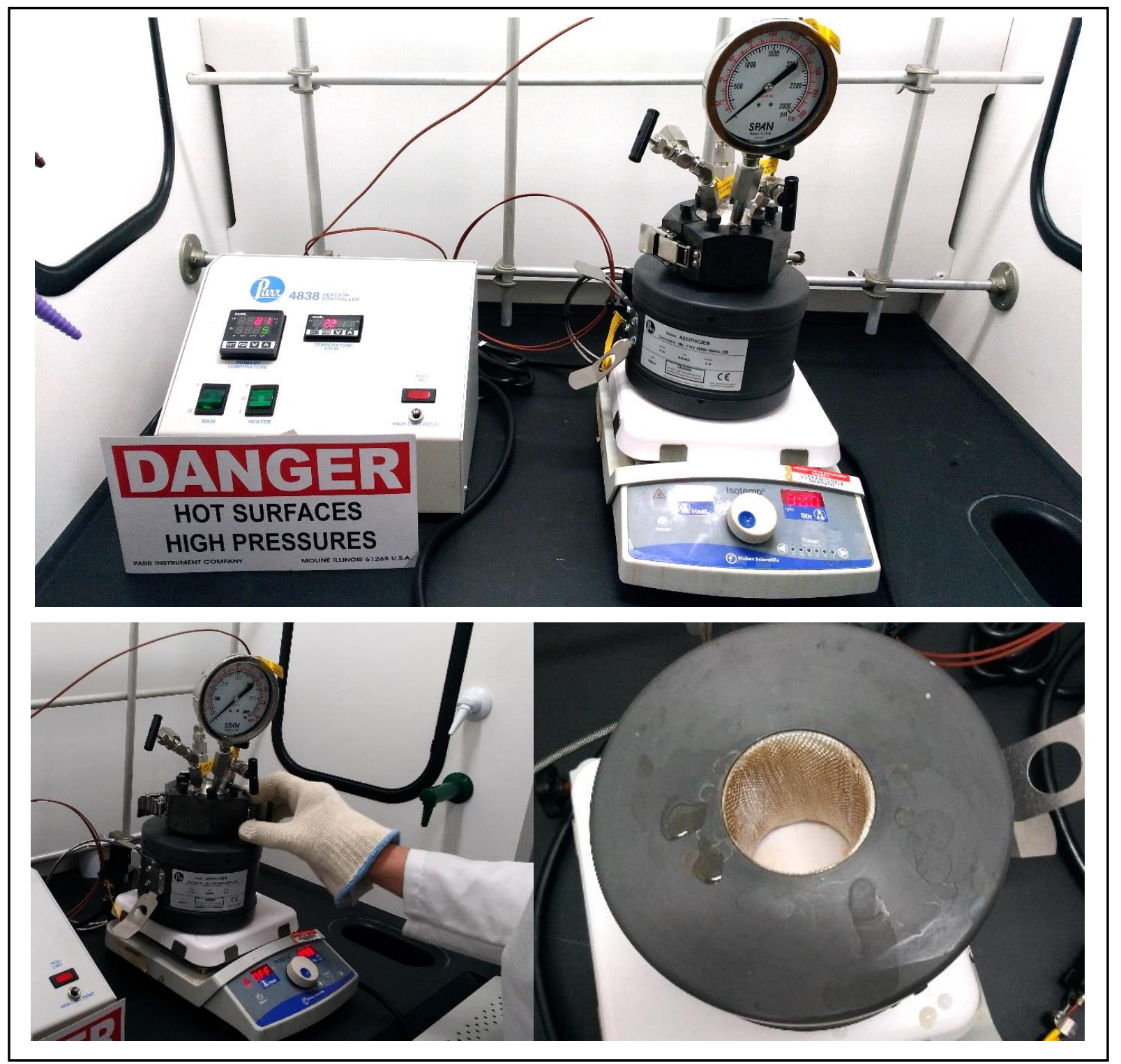

Figure 3. Water vaporization rate experimental setup. The heating jacket is shown in the bottom right figure.

The issues with trying to determine the rate of vaporization using such an experimental setup are

- The actual heat losses from the heating mantel to the surroundings through conduction, convection, and radiation are unknown.

- The actual value of heat flux from the heating mantel to the reactor was unavailable. 
- The actual area of contact between the heating mantel and the reactor is unknown.

- The pressure gage mounted on the reactor was having a measurement range too high to properly capture the pressure rise inside the reactor throughout the vaporization process. Specifically, the minimum pressure that could be read on the gauge was 8 bar.

However, some assumptions were made for the experiment such as:

- The measured surface area of the reactor assumed to be in contact with the heating mantel heater was $0.02 \mathrm{~m}^{2}$.

- $\quad$ Based on these approximated contact area, the heat flux was assumed to be equal to 18.8 $\mathrm{kW} / \mathrm{m}^{2}$.

\subsection{CFD software}

A research version of ANSYS ${ }^{\circledR}$ Fluent CFD software, Versions 17.2 and 18.2, was used in this thesis. The CFD software's default meshing was used for geometry and mesh generation. Solidworks ${ }^{\circledR}$ was used to design the $3 \mathrm{D}$ models for the moving mesh model, and meshing was done in default ANSYS® Fluent meshing software.

\subsection{Model geometry and mesh generation}

ANSYS $®$ CFD default meshing was used for mesh generation. Computational domains were created based on the actual reactor geometry and dimensions. However, the initial models used a simplified geometry to better understand the effects of various parameters used in the simulation. The final reactor simulation was obtained after incorporating these initial models. All models assume fluids to be fully compressible.

\subsubsection{Model description and properties of constituents}

Figure 4 shows the reactor schematics. While the reactor is cylindrical, the simulation used the axisymmetric option to reduce simulation time and meshing complexity. Heat was applied to the side reactor surfaces, keeping the top and bottom surfaces adiabatic. The central volume contains the reacting species, the catalyst, and the paddle used to improve mixing. 


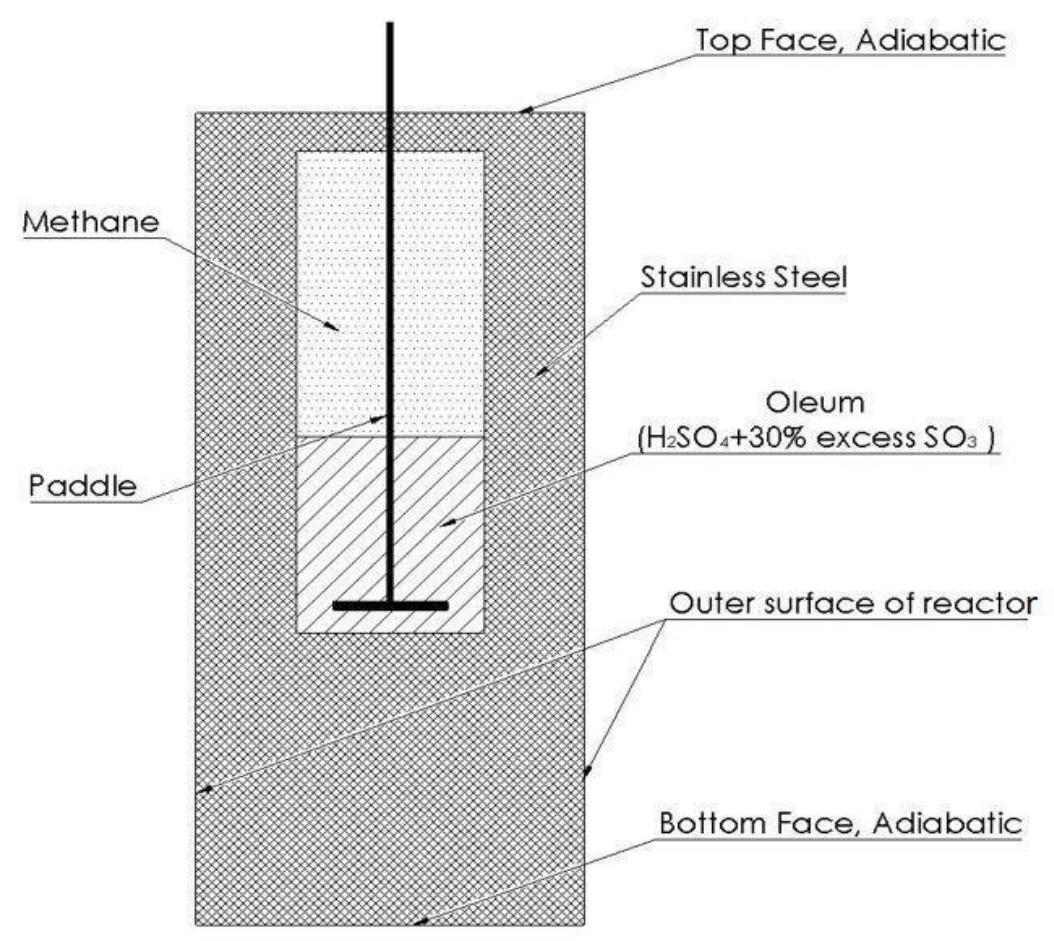

Figure 4. 2-D cross section of the reactor with paddle

As seen in Figure 4, methane occupied most of the reactor volume, with the rest being $30 \%$ Oleum ( $\mathrm{H} 2 \mathrm{SO} 4,30 \%$ free $\mathrm{SO} 3$ basis). In the experiment, a platinum catalyst in porous form enabled the chemical reaction between methane and oleum. However, since the catalyst mass was negligible compared to the reactants and did not affect the heat transfer, the catalyst was not included in the simulation. Figures 5 and 6 show the reactor used in the experiment.

Similar to the procedure described in Ref. [24], a heat flux was applied to the exterior surface. Once the conditions inside the reactor are optimal, the chemical reaction between $\mathrm{SO}_{3}$ and $\mathrm{CH}_{4}$ gets initiated. $\mathrm{SO}_{3}$ must vaporize before reacting with $\mathrm{CH}_{4}$, which is possible due to $\mathrm{SO}_{3}$ having a boiling point lower than $488 \mathrm{~K}$. As a result, the simulation must be capable of modeling multiphase phenomena. However, this is not trivial, as it must resolve the dynamic behavior of the interface between the fluids and require a much more detailed meshing than the one used for single phase phenomena. To understand how Ansys ${ }^{\circledR}$ Fluent works in such cases, a simple model that used a fluid of known properties, like water, was investigated. Once the rate of vaporization was understood and validated in terms of the heating time, temperature gradients, and wall heat fluxes, the simulation was repeated using $\mathrm{SO}_{3}$ to predict its evaporation rate. In these simulations, the wall heat transfer was done in a separate model that predicts the time needed by the external heating 
element to raise the temperature inside the reactor to $488 \mathrm{~K}$. Each of these models is described below.

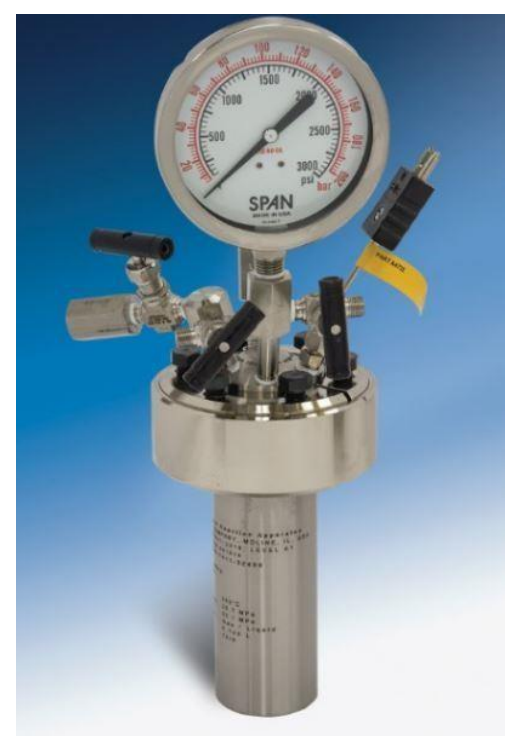

Figure 5. Reactor used for methane-to-methanol synthesis

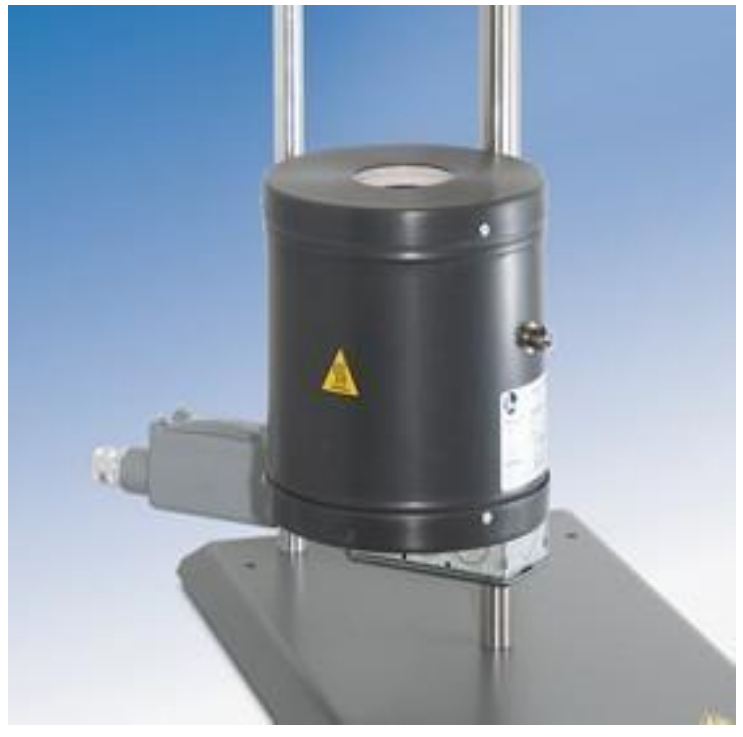

Figure 6. Reactor heating mantle 
Table 1. Reactor dimensions.

\begin{tabular}{|l|l|}
\hline Reactor volume $[\mathrm{ml}]$ & 26 \\
\hline Oleum volume $[\mathrm{ml}]$ & 16 \\
\hline Reactor dimensions & 2" dia. x 3.54” long \\
\hline
\end{tabular}

Table 2. Reactant properties [24]

\begin{tabular}{|l|c|c|}
\hline \multicolumn{1}{|c|}{ Property } & Oleum $\left(\mathbf{H}_{\mathbf{2}} \mathbf{S O}_{\mathbf{4}}+\mathbf{3 0 \%} \mathbf{S O}_{3}\right)$ & Methane $\left(\mathrm{CH}_{\mathbf{4}}\right)$ \\
\hline Density $\left(\mathrm{kg} / \mathrm{m}^{3}\right)$ & 1840 & 0.6679 \\
\hline Specific Heat $(\mathrm{J} / \mathrm{Kg}-\mathrm{K})$ & 1550 & 2222 \\
\hline Thermal Conductivity (W/m-K) & 2.43 & 0.0332 \\
\hline Viscosity (Kg/m-s) & 0.048 & $1.087 \mathrm{e}-05$ \\
\hline Molecular Weight & 98.082 & 16.04303 \\
\hline
\end{tabular}

\subsubsection{Water evaporation model}

Figures 7 and 8 show the geometry and mesh of the model used to simulate fluid vaporization inside the reactor using water as working fluid. Table 3 presents the model mesh properties. As mentioned in table 3 caption, same meshing parameters were used for the $\mathrm{SO}_{3}$ vaporization model, which will be discussed later. To simplify the problem, the reactor was partially filled with fluid and a heat flux of $3520 \mathrm{~W} / \mathrm{m}^{2}$ was input through the base. The initial water temperature inside the reactor was $373 \mathrm{~K}$. The top surface and side walls were adiabatic. The simulation was run for 30 seconds and the rate of water vaporization, pressure inside the reactor, and mass of the mixture phases (i.e., liquid and vapor) were observed. 


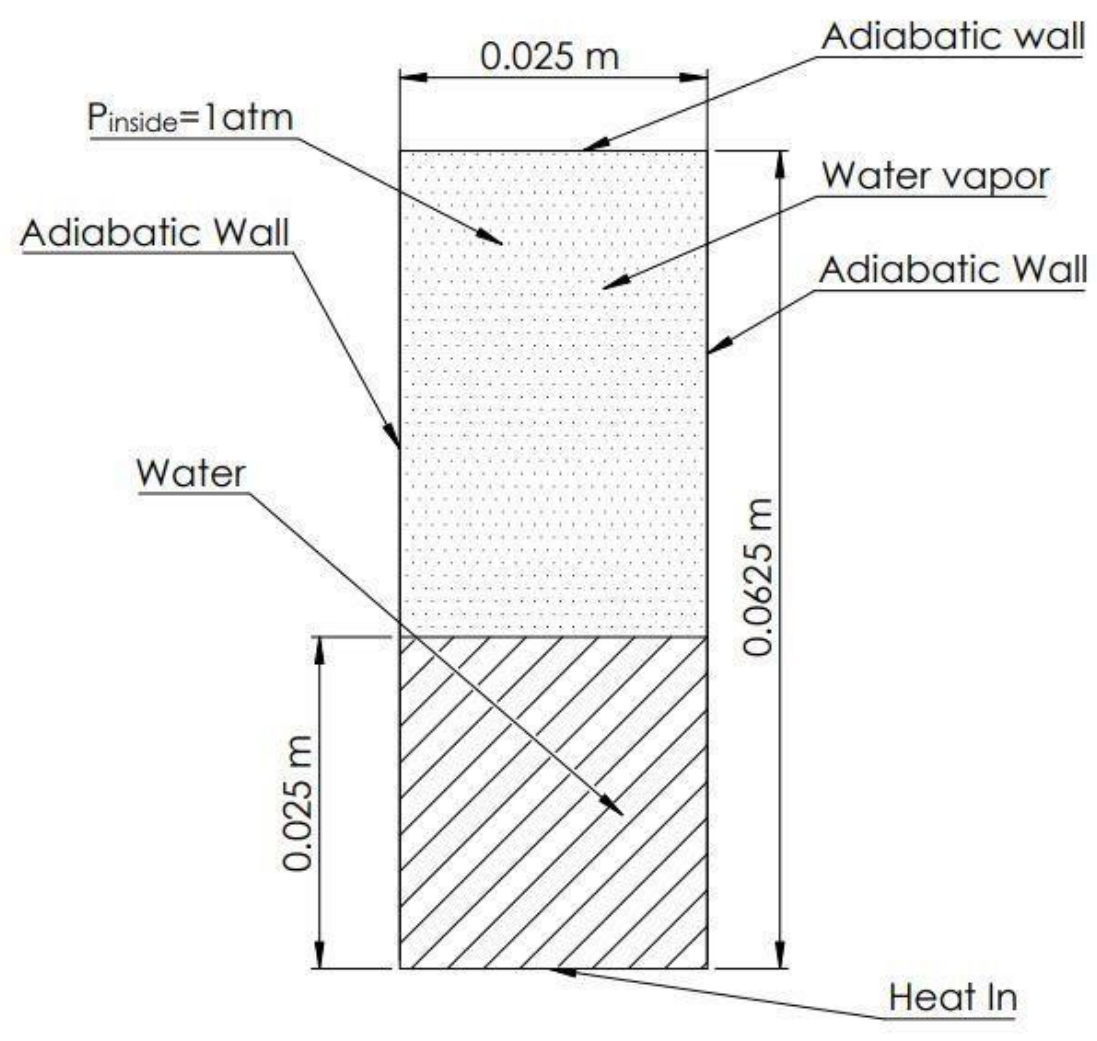

Figure 7. Schematic of the water evaporation model

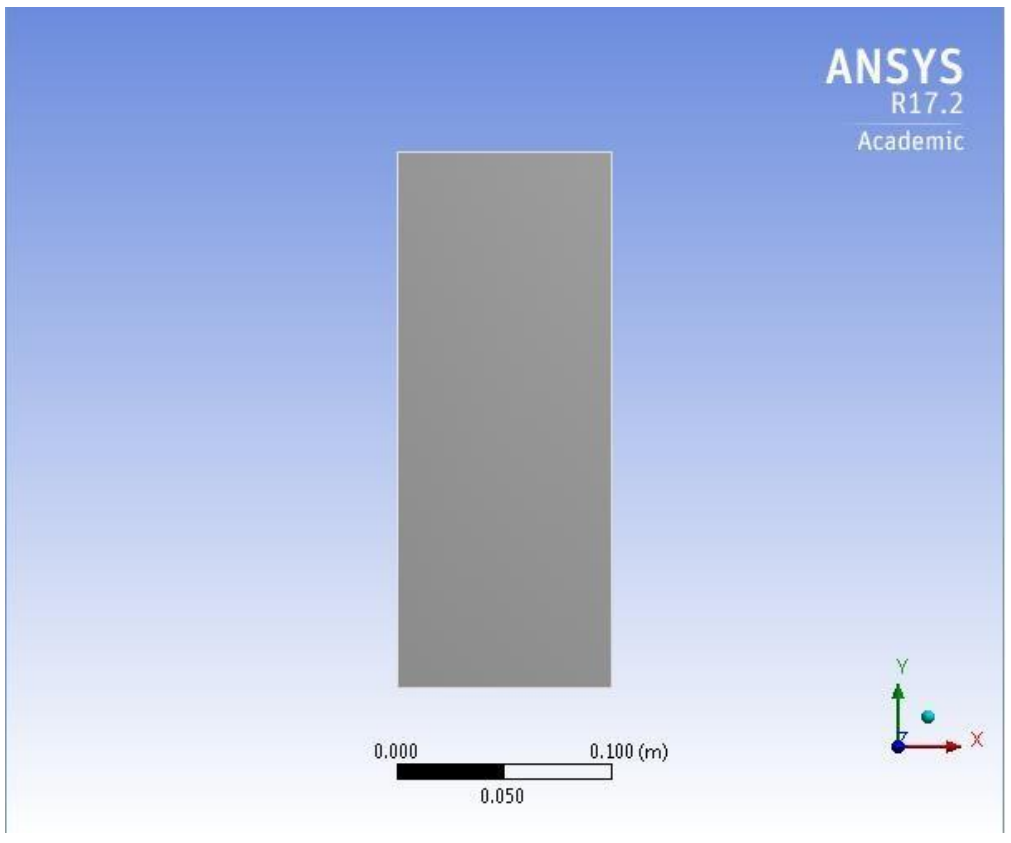

Figure 8. Geometry of water evaporation model 
Table 3. Mesh properties for water and sulfur trioxide vaporization models

\begin{tabular}{|r|c|}
\hline Object Name & Mesh properties \\
\hline Size Function & Uniform \\
\hline Relevance Center & Fine \\
\hline Initial Size Seed & Active Assembly \\
\hline Smoothing & High \\
\hline Min Size & Default (9.82e-6 m) \\
\hline Max Face Size & Default (9.82e-4 m) \\
\hline Growth Rate & Default (1.0 ) \\
\hline Nodes & Statistics \\
\hline Elements & 1690 \\
\hline
\end{tabular}

Table 4. Mesh properties for reactor heating model

\begin{tabular}{|r|c|}
\hline Object Name & Mesh properties \\
\hline Size Function & Curvature \\
\hline Relevance Center & Fine \\
\hline Initial Size Seed & Active Assembly \\
\hline Smoothing & Medium \\
\hline Min Size & Default (1.36e-5 m) \\
\hline Max Face Size & Default (1.3e-3 m) \\
\hline Growth Rate & Default (1.2 ) \\
\hline Nodes & Statistics \\
\hline Elements & 20405 \\
\hline
\end{tabular}




\subsection{3. $\mathrm{SO}_{3}$ liquid-to-vapor phase change}

The model shown in Figure 9 investigated the rate of $\mathrm{SO}_{3}$ evaporation when heat flux of $3520 \mathrm{~W} / \mathrm{m}^{2}$ is applied to the bottom wall. The simulation was similar to the one used to observe water vaporization. The initial volume of liquid $\mathrm{SO}_{3}$ in the container was 0.625 l. The initial $\mathrm{SO}_{3}$ temperature inside the reactor was $318 \mathrm{~K}$. The top surface was assumed to be adiabatic. The simulation was run for 3 seconds and the rate of $\mathrm{SO}_{3}$ vaporization, pressure inside the reactor, and mass of the mixture phases (i.e., liquid and vapor) were observed. More, the simulation also investigated the effect of surface tension on the $\mathrm{SO}_{3}$ vaporization.

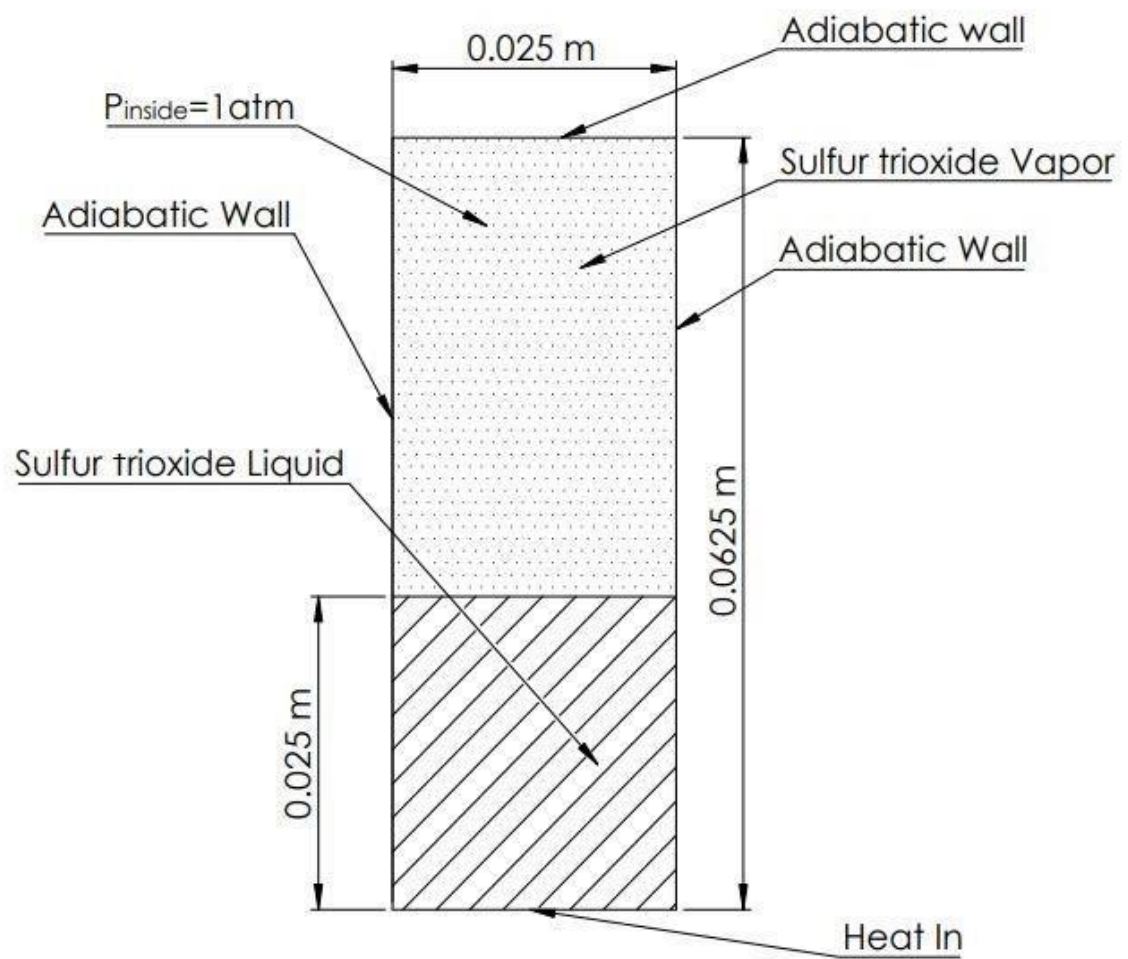

Figure 9. Schematic of $\mathrm{SO}_{3}$ evaporation model 


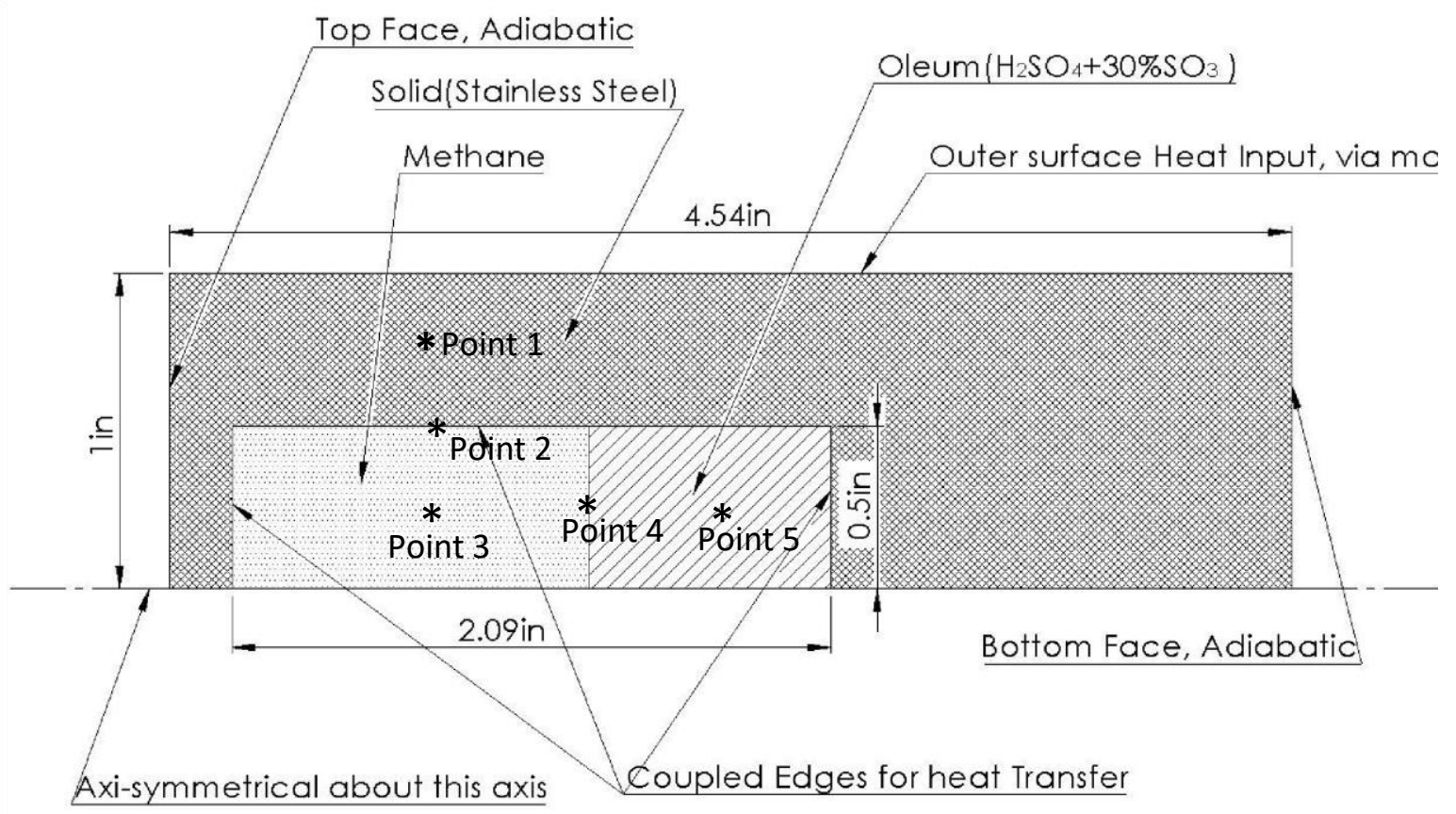

Figure 10. Schematic of heat transfer via mantel

\subsubsection{Heat transfer through the reactor via heating mantel}

Figure 10 shows the model used to simulate the heat transfer through the reactor walls from the heating mantel. The initial reactor temperature was $300 \mathrm{~K}$. The heat flux simulated the electric heating from the heating mantel. The operating pressure inside the reactor was 101,325 $\mathrm{Pa}$. The simulation output was the temperature distribution inside the reactor at different locations of interest. First, the simulation ended when the inside reactor temperature reached $488 \mathrm{~K}$. Next, the simulation investigated the change in reactor temperature over a period of 10 minutes.

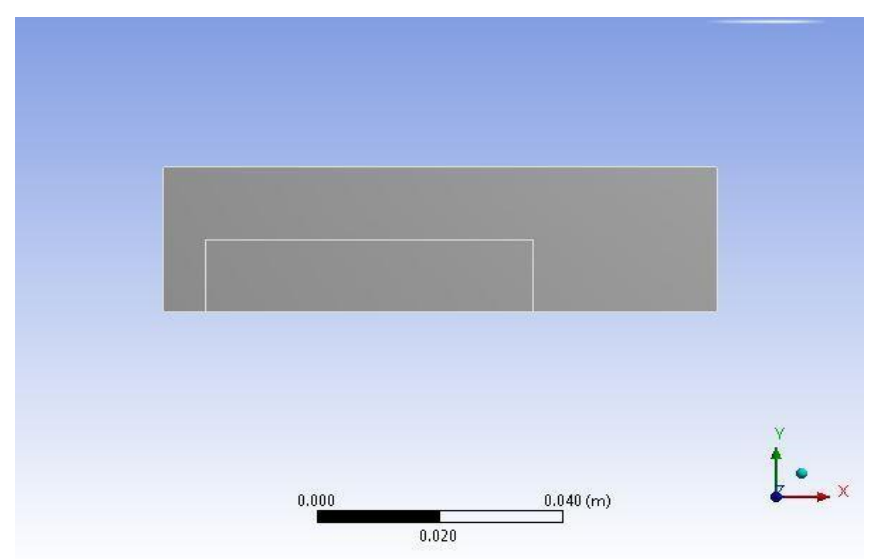

Figure 11. Geometry of the reactor without mixing paddle 


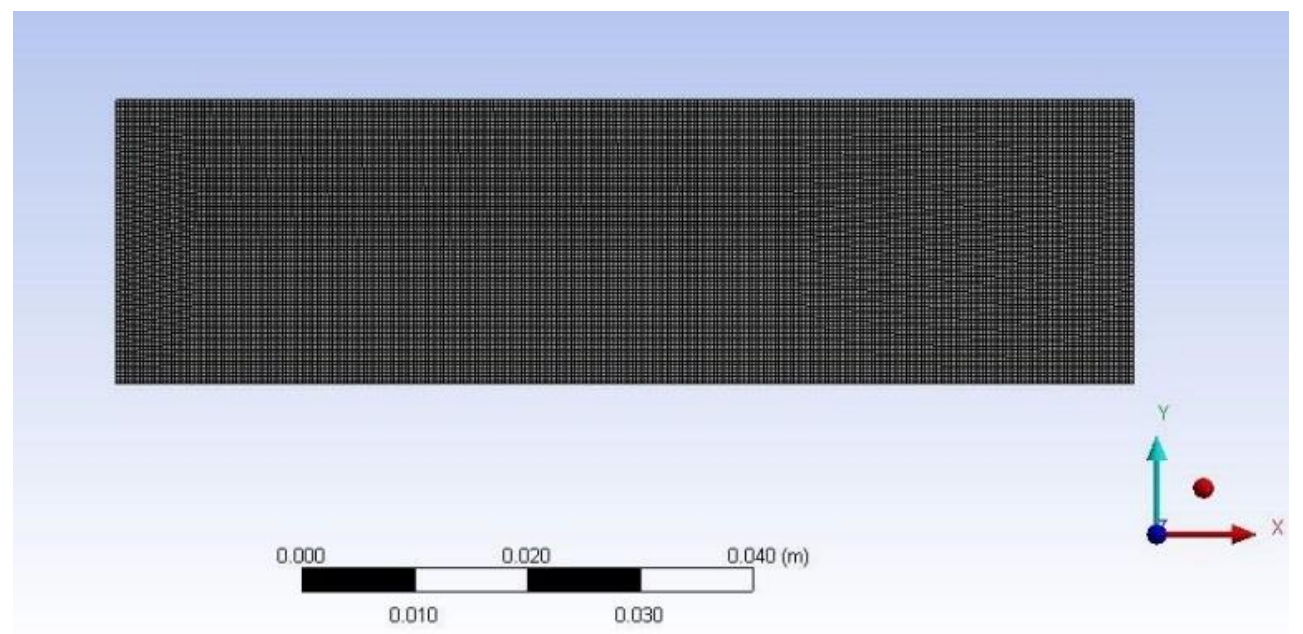

Figure 12. Mesh for the reactor with mixing paddle

In addition, a moving mesh was used to simulate the motion of the mixing paddle inside the reactor.

\subsection{Simulation settings}

Ansys ${ }^{\circledR}$ Fluent simulations were run using the pressure-based coupled solver (with gravity enabled). While a steady state simulation is much less time consuming than a transient simulation, the multiphase flows often exhibit transient behavior. As a result, forcing a transient flow to a steady state might produce an unphysical solution. Subsequently, a transient simulation was therefore run to investigate the transient behavior. The time step size was $0.001 \mathrm{~s}$ for all the simulations. Table 5 shows the list of simulation settings used.

Table 5. Simulation settings

\begin{tabular}{|l|l|l|}
\hline No & Setting & Type \\
\hline 1 & Scheme & SIMPLE \\
\hline 2 & Gradient & Least Squares cell based \\
\hline 3 & Pressure & Presto \\
\hline 4 & Momentum & Second order upwind \\
\hline 5 & Volume Fraction & Geo-Reconstruct \\
\hline 6 & Energy & Second order upwind \\
\hline 7 & Transient Formulation & First Order Implicit \\
\hline
\end{tabular}




\subsection{Boundary conditions}

All exterior reactor surfaces were adiabatic except the bottom surface, for both the water and $\mathrm{SO}_{3}$ model. Heat was input from the bottom and the top surface acted as a pressure outlet. There were no fluid inlets or outlets. The reactor was filled with the working fluid(s) at time $t=0$, and the vapor and liquid regions were identified.

The heating mantel model was run in an axisymmetric configuration. It had adiabatic walls except for the one through which heat transfer occurred, and no pressure outlets. Except this difference, the rest of the conditions were the same as those for the water model.

\subsection{Model convergence criteria}

The model convergence was also assessed by monitoring the evaporation rate and reactor temperature. As previously mentioned, the methane-to-methanol synthesis experimental reactor was kept at a pressure of 40 bar for 2.5 hours after reaching a temperature of $488 \mathrm{~K}$. However, since this was a proof of concept project, simulation variables like reaction rate, mole fraction of reactants at each step, and catalyst consumption were unknown. As a result, the simulation duration was based on the heat transfer through the mantel and the rate of temperature rise. Regardless, simulations are computer intensive, so the simulation was usually run until the reactor reached $488 \mathrm{~K}$.

\subsection{Simulation evaluation criteria}

Several criteria can be used to assess simulation results. A more complex model improves results accuracy at the expense of long calculation times. For example, a faster simulation yielding a basic understanding of the problem can be enough for a preliminary investigation, even if a more complex model would produce more accurate results. However, for a detailed study the accuracy of the simulations is probably more important than time requirement. As a result, the simulations presented in this work were analyzed based on accuracy, convergence and time requirement. The time requirement criterion was straightforward. If a simulation converged fast it was judged as "good" with respect to time. The accuracy of the results was based on how well the model predicted known phenomena or values. On the other hand, if the model reduced the underrelaxation factors or use other methods for better numerical convergence, then the simulation was considered "less good" with respect to stability. 


\section{Chapter 3. Results and discussions}

This section presents the simulation results and compare them with the available experimental data. Section 3.1 discuss and compare the experimental and simulated vaporization rates inside the reactor using water as phase-change medium. In addition, the results of the water vaporization experiment were compared to the predictions of a simple phase-change thermodynamic model. Section 3.2 discuss and compare the vaporization rates inside the reactor using sulfur trioxide as phase-change medium. Section 3.3 presents and discusses the time required to heat the reactor to the temperature required for optimum methane-to-methanol synthesis. The predicted parameters are then compared to experimental data, and the differences are discussed. Finally, different cases for optimum heat exchange are discussed and a design recommendation is suggested based on the results of the heat exchanger (i.e., heating mantel) simulation.

\subsection{Water vaporization}

As mentioned in Section 2.1.2, a water vaporization experiment was performed to estimate the heating parameters used in the CFD simulation. Figure 13 shows the reactor-content temperature change with time during the water vaporization experiment. As expected, the measured temperature followed the well-known phase change T-V diagram at a constant pressure. The temperature increase after $688 \mathrm{~s}$ suggests that all the water liquid inside the reactor was vaporized at that instant. To check if the assumptions made for the heating mantel power and surface contact area were correct, a thermodynamic model was built in MATLAB $®$. The MATLAB $®$ code for can be found in the Appendix. The model calculated the mass of water evaporated in a specific period and compared it with the experiment. The experiment estimated a heat transfer rate to the reactor of $350 \mathrm{~W}$ over a surface contact area of $0.02 \mathrm{~m}^{2}$. The thermodynamic model considered that the volume of liquid inside the reactor was $25 \mathrm{ml}$ and the rest of the volume (i.e., $75 \mathrm{ml}$ ) was filled with saturated vapor at $373 \mathrm{~K}$ and $101,325 \mathrm{kPa}$. The model used the following equations:

$$
\begin{aligned}
\dot{m}_{v} & =\frac{\dot{Q}_{\text {in }}[W]}{H_{L V}[\mathrm{~J} / \mathrm{Kg}]} \\
m_{\text {total }} & =m_{\text {vapor }}+m_{\text {liquid }} \\
V_{\text {liquid }} & =\frac{m_{\text {liquid }}}{\rho_{\text {liquid }}}
\end{aligned}
$$




$$
\begin{aligned}
P V_{\text {vapor }} & =m_{\text {vapor }} R T_{\text {vapor }} \\
V_{\text {liquid }}+V_{\text {vap }} & =V_{\text {total }}
\end{aligned}
$$

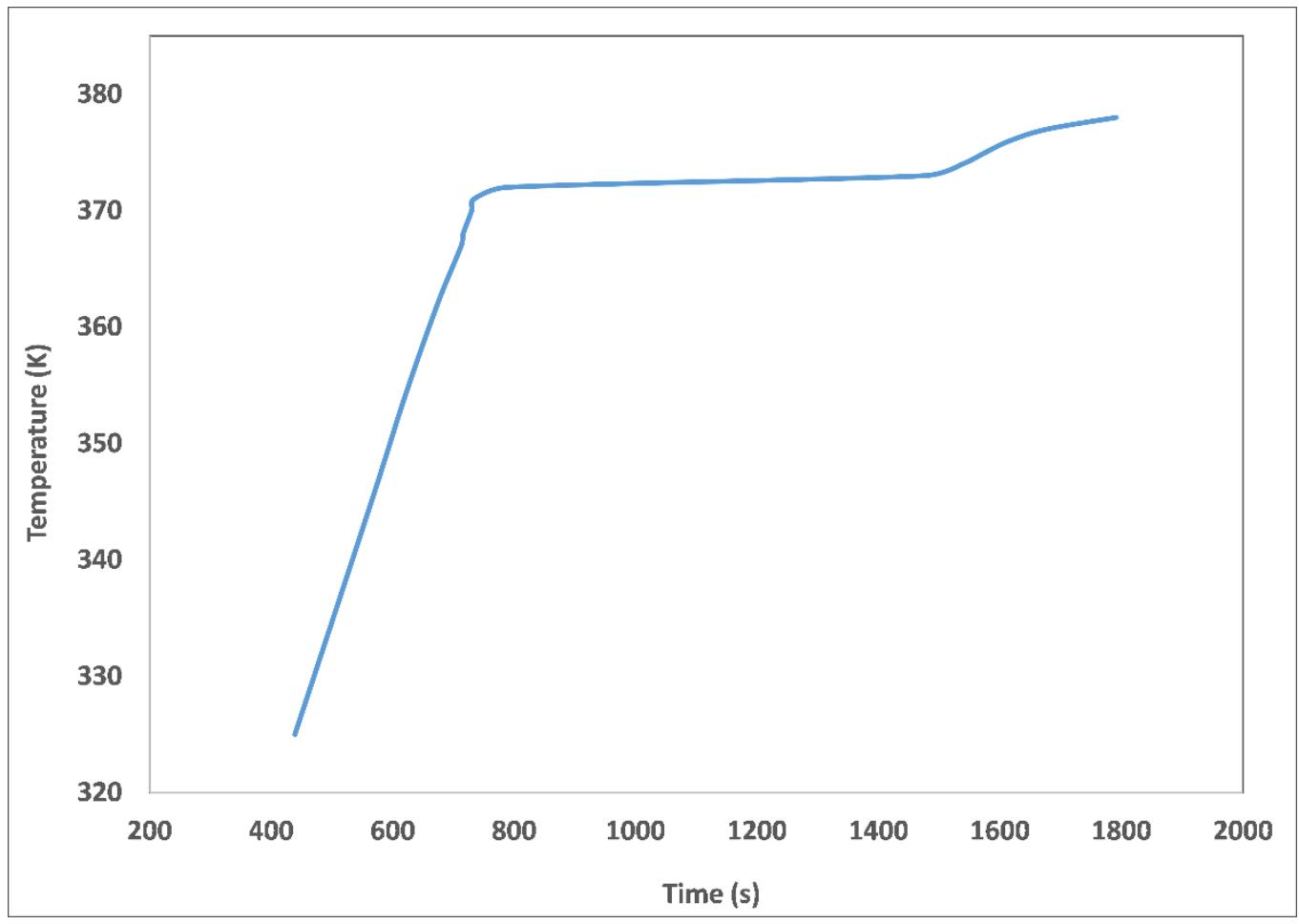

Figure 13. Reactor-content temperature change with time during the water vaporization experiment

The thermodynamic model predicted that the heat transfer rate that would vaporize $25 \mathrm{ml}$ of water in $688 \mathrm{~s}$ is $88 \mathrm{~W}$ compared to the manufacturer-rated power of $350 \mathrm{~W}$. While there was a $75 \%$ difference between the experiment and thermodynamic model, the thermodynamic model results were probably very different form the actual heat transfer rate. More, the difference was probably due to heat losses in the experiment through conduction, convection, and radiation.

The lower heat transfer rate of $88 \mathrm{~W}$ that predicted by the thermodynamic model was used as an input in the ANSYS $®$ Fluent vaporization models. Two different models were run. The main difference between these two models was the time step used. The simulation time for the first model was $30 \mathrm{~s}$ and the pressure inside the reactor was $101,325 \mathrm{~Pa}$. A heat flux of $3520 \mathrm{~W} / \mathrm{m}^{2}$ corresponded to the heat transfer rate determined with the thermodynamic model. The time step size was $0.001 \mathrm{~s}$ and maximum number of iteration was 200 . The simulation observed the water vaporization as function of time and the results were compared to the experimental. 
Table 6. Comparison of properties used for experiment and simulation

\begin{tabular}{|l|l|l|}
\hline Property & Experiment & Simulation \\
\hline Heat transfer rate (applied)(W) & 350 & 88 \\
\hline Heat loss $(\mathrm{W})$ & 262 & 0 \\
\hline Heat Flux $\left(\mathrm{W} / \mathrm{m}^{2}\right)$ & 17500 & 3520 \\
\hline Vaporization rate $(\mathrm{ml} / \mathrm{s})$ & 0.036 & 0.012 \\
\hline Surface area of heat transfer $\left(\mathrm{m}^{2}\right)$ & 0.02 & 0.025 \\
\hline Initial mass of liquid $(\mathrm{g})$ & 25 & 635.25 \\
\hline Initial mass of vapor $(\mathrm{g})$ & 0 & 0.51 \\
\hline Final mass of liquid $(\mathrm{g})$ & 0 & 0 \\
\hline Final mass of vapor $(\mathrm{g})$ & 25 & 0.36 \\
\hline
\end{tabular}

Figure 14 presents the volume fraction of water at seven instances, ranging from $t=0 \mathrm{~s}$ to $t=$ $30 \mathrm{~s}$. The first image $(t=0 \mathrm{~s})$ shows that the amount of water and vapor initially present. The temperature of water increases gradually between $1 \mathrm{~s}$ and $3 \mathrm{~s}$, but no significant changes were seen. The first vapor bubbles appeared at $t=5 \mathrm{~s}$ and distinctive bubbles rise from the bottom of the container and started perturbing the interface. The vaporization process at $t=10 \mathrm{~s}$ seems to be rapid. The vapor bubbles continued to move upwards rapidly, and vaporization continues at $t=15 \mathrm{~s}$. The amount of liquid is very small $t=25 \mathrm{~s}$. The liquid completely vaporized at $t=30 \mathrm{~s}$. The table below shows the mass of liquid and vapor at different instances.

The next model was simulated for a timestep size 10x smaller than previous. The simulation was only run for $5 \mathrm{~s}$ since the simulation time increases exponentially at a smaller time step. The objective was to compare the effects of timestep size on vaporization rate. Table 7 shows the values of mass of liquid and vapor at the end of 5 seconds with different timesteps. The vaporization frequency in the model used was $r=0.1$.

The simulation results indicated that:

- A smaller time step increases the vaporization rate

- The simulation did not conserve mass. Specifically, the observed vapor mass increase was only due to increased volume at constant density and not due to the phase change. 
Volume fraction of liquid

$1.00 \mathrm{e}+00$
$9.50 \mathrm{e}-01$
$9.00 \mathrm{e}-01$
$8.50 \mathrm{e}-01$
$8.00 \mathrm{e}-01$
$7.50 \mathrm{e}-01$
$7.00 \mathrm{e}-01$
$6.50 \mathrm{e}-01$
$6.00 \mathrm{e}-01$
$5.50 \mathrm{e}-01$
$5.00 \mathrm{e}-01$
$4.50 \mathrm{e}-01$
$4.00 \mathrm{e}-01$
$3.50 \mathrm{e}-01$
$3.00 \mathrm{e}-01$
$2.50 \mathrm{e}-01$
$2.00 \mathrm{e}-01$
$1.50 \mathrm{e}-01$
$1.00 \mathrm{e}-01$
$5.00 \mathrm{e}-02$
$0.00 \mathrm{e}+00$
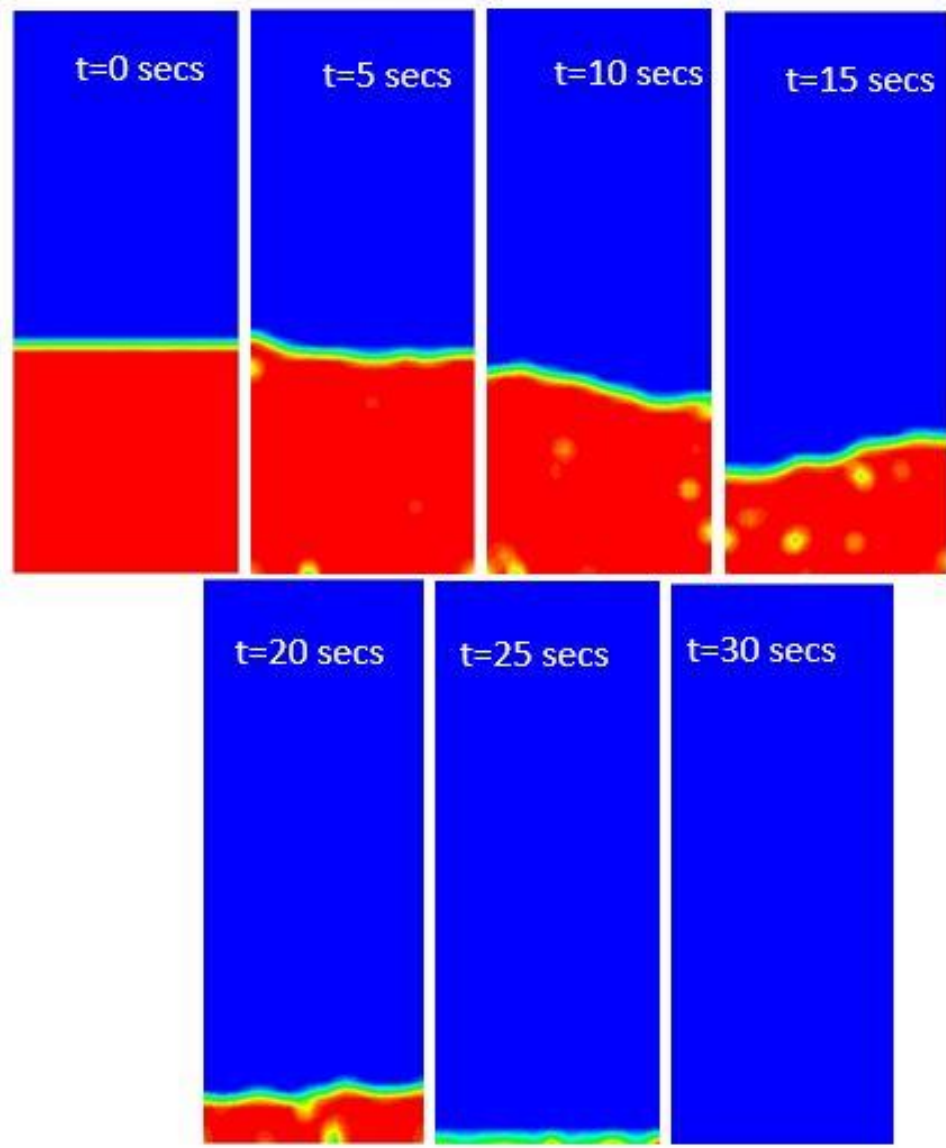

Figure 14. Liquid water volume fraction

Table 7. Comparison of mass of liquid and vapor with different time step values

\begin{tabular}{|l|l|l|l|}
\hline \multicolumn{4}{|c|}{ Time step size 0.001 } \\
\hline Time $(\mathrm{s})$ & Mass of vapor $(\mathrm{g})$ & Mass of liquid $(\mathrm{g})$ & Total mass $(\mathrm{g})$ \\
\hline 0 & 0.51 & 634.7 & 635.2 \\
\hline 5 & 0.53 & 607.6 & 608.1 \\
\hline 10 & 0.58 & 510.2 & 510.7 \\
\hline 15 & 0.69 & 319.2 & 319.9 \\
\hline 20 & 0.79 & 131.5 & 132.3 \\
\hline 25 & 0.86 & 7.4 & 82 \\
\hline 30 & 0.87 & 0 & 0.8 \\
\hline
\end{tabular}


Table 8. Predicted water liquid and vapor mass after $30 \mathrm{~s}$

\begin{tabular}{|r|r|r|r|r|r|r|}
\hline & \multicolumn{3}{|c|}{0.001 timestep } & \multicolumn{3}{c|}{0.0001 timestep } \\
\hline $\begin{array}{l}\text { Time } \\
(\mathrm{s})\end{array}$ & $\begin{array}{l}\text { Mass of } \\
\text { vapor }(\mathrm{g})\end{array}$ & $\begin{array}{l}\text { Mass of } \\
\text { liquid }(\mathrm{g})\end{array}$ & Total mass $(\mathrm{g})$ & $\begin{array}{l}\text { Mass of } \\
\text { vapor }(\mathrm{g})\end{array}$ & $\begin{array}{l}\text { Mass of } \\
\text { liquid } \\
(\mathrm{g})\end{array}$ & $\begin{array}{l}\text { Total mass } \\
(\mathrm{g})\end{array}$ \\
\hline 0 & 0.51 & 634.7 & 635.2 & 0.51 & 634.7 & 635.2 \\
\hline 1 & 0.52 & 631.7 & 632.2 & 0.51 & 631.6 & 632.2 \\
\hline 2 & 0.52 & 624.3 & 624.8 & 0.52 & 624.2 & 624.4 \\
\hline 3 & 0.53 & 619.5 & 620 & 0.52 & 619.2 & 619.7 \\
\hline 4 & 0.53 & 614.2 & 614.6 & 0.53 & 611.7 & 612.2 \\
\hline 5 & 0.54 & 607.6 & 608.2 & 0.53 & 603.9 & 604.4 \\
\hline
\end{tabular}

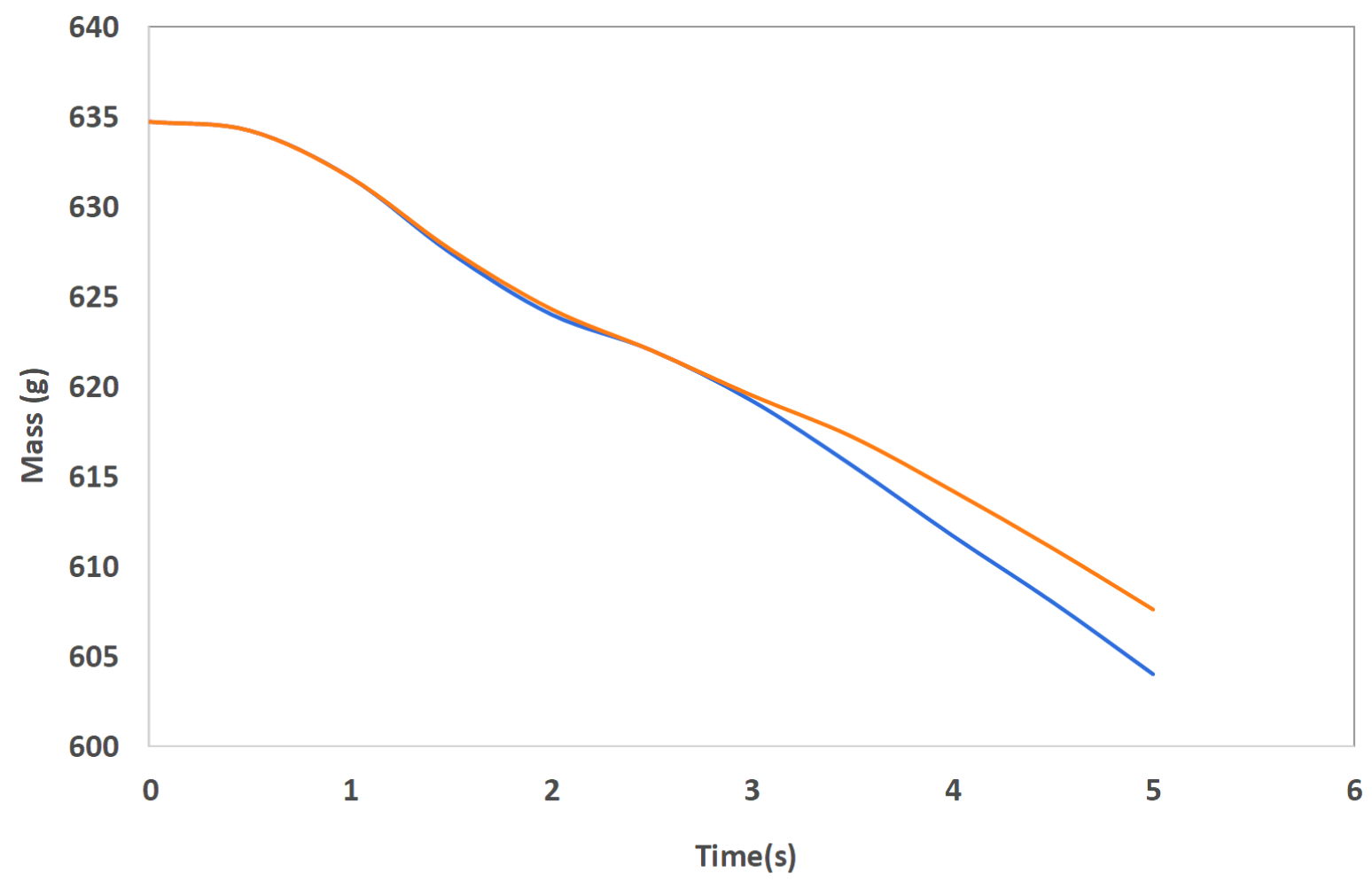

— Timestep size 0.0001 — Timestep size 0.001

Figure 15. Effect of timestep on liquid vaporization 


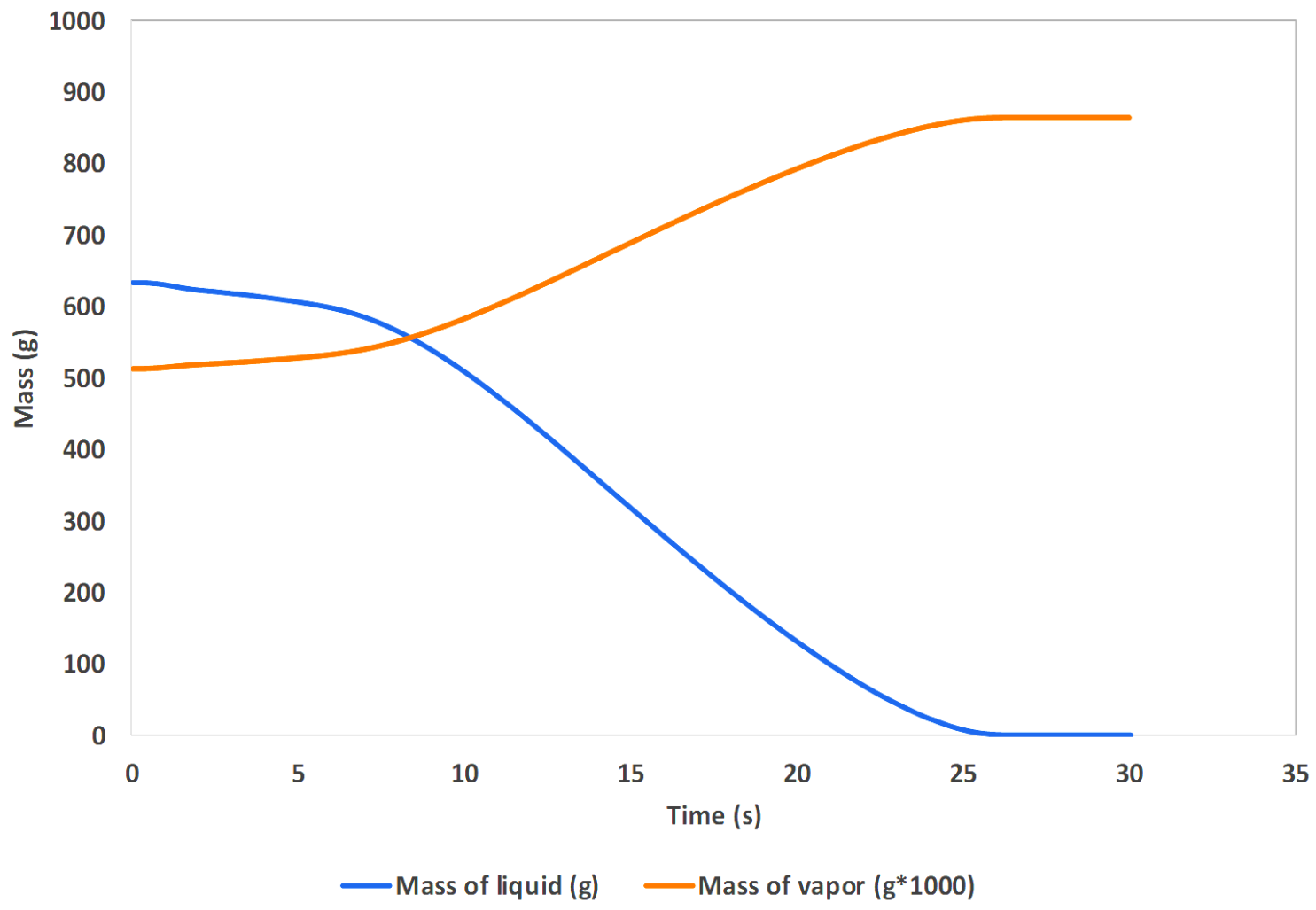

Figure 16. Mass of liquid and vapor inside the reactor (0.001 s timestep)

\section{2 $\mathrm{SO}_{3}$ vaporization}

Using the knowledge accumulated from the water vaporization model, the $\mathrm{SO}_{3}$ vaporization was simulated next. Two models were run. The first model did not consider the surface tension and was run for 3 seconds. The time step size was $0.0001 \mathrm{~s}$ and the maximum number of iterations was 200 . The heat flux value was $3520 \mathrm{~W} / \mathrm{m}^{2}$ and the pressure was $101,325 \mathrm{~Pa}$. The second model was run for 3 seconds with surface tension of $0.001 \mathrm{~N} / \mathrm{m}$ and with the same properties and timestep. For the same amount of heat transfer rate, the vaporization observed in the simulation model was compared.

Figure 16 presents the volume fraction of $\mathrm{SO}_{3}$ at time instances ranging from $t=0 \mathrm{~s}$ to $t=3 \mathrm{~s}$, in the absence of surface tension effects. A change just above the bottom surface is seen at $t=0.5 \mathrm{~s}$. From $\mathrm{t}=1.5$ to $3 \mathrm{~s}$, vapor starts forming and increases gradually.

Figure 17 presents the volume fraction of $\mathrm{SO}_{3}$ at time instances ranging from $t=0 \mathrm{~s}$ to $t=3 \mathrm{~s}$, in the presence of surface tension effects. At $t=0 \mathrm{~s}$, the amount of liquid and vapor is shown. Tiny 
vapor bubbles start to form and stick to the bottom surface at $t=1 \mathrm{~s}$. As time progresses, the size of bubbles keeps increasing but they do not rise to the interface.

The difference in both the simulations is that when there was no surface tension, the vapor was spread over the bottom surface but when surface tension is applied, the vapor accumulates into smaller bubbles and slowly coalesce but do not leave the surface.

Table 9. Predicted $\mathrm{SO}_{3}$ liquid and vapor mass after $3 \mathrm{~s}$

\begin{tabular}{|l|l|l|l|l|l|l|}
\hline & \multicolumn{4}{|l|}{ Without surface tension } & \multicolumn{2}{l|}{ With surface tension } \\
\hline Time $(\mathrm{s})$ & $\begin{array}{l}\text { Mass of } \\
\text { vapor }(\mathrm{g})\end{array}$ & $\begin{array}{l}\text { Mass of } \\
\text { liquid }(\mathrm{g})\end{array}$ & $\begin{array}{l}\text { Total mass } \\
(\mathrm{g})\end{array}$ & $\begin{array}{l}\text { Mass of } \\
\text { vapor }(\mathrm{g})\end{array}$ & $\begin{array}{l}\text { Mass of } \\
\text { liquid }(\mathrm{g})\end{array}$ & $\begin{array}{l}\text { Total mass } \\
(\mathrm{g})\end{array}$ \\
\hline 0 & 0.94 & 1.18 & 2.13 & 0.94 & 1.18 & 2.13 \\
\hline 0.5 & 0.94 & 1.18 & 2.13 & 0.94 & 1.18 & 2.13 \\
\hline 1 & 0.95 & 1.18 & 2.12 & 0.95 & 1.18 & 2.13 \\
\hline 1.5 & 0.95 & 1.17 & 2.12 & 0.95 & 1.17 & 2.12 \\
\hline 2 & 0.95 & 1.17 & 2.12 & 0.95 & 1.17 & 2.12 \\
\hline 2.5 & 0.95 & 1.16 & 2.12 & 0.95 & 1.16 & 2.12 \\
\hline 3 & 0.96 & 1.16 & 2.11 & 0.96 & 1.16 & 2.11 \\
\hline
\end{tabular}


Volume fraction of liquid

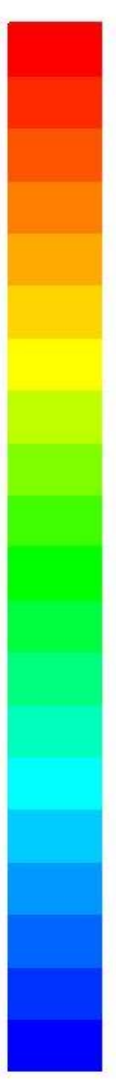
$1.00 \mathrm{e}+00$
9.50e-01
9.00e-01
8.50e-01
8.00e-01
$7.50 \mathrm{e}-01$
$7.00 \mathrm{e}-01$
6.50e-01
6.00e-01
5.50e-01
5.00e-01
4.50e-01
4.00e-01
3.50e-01
3. $00 \mathrm{e}-01$
2.50e-01
2.00e-01
$1.50 \mathrm{e}-01$
$1.00 \mathrm{e}-01$
5.00e-02
$0.00 e+00$
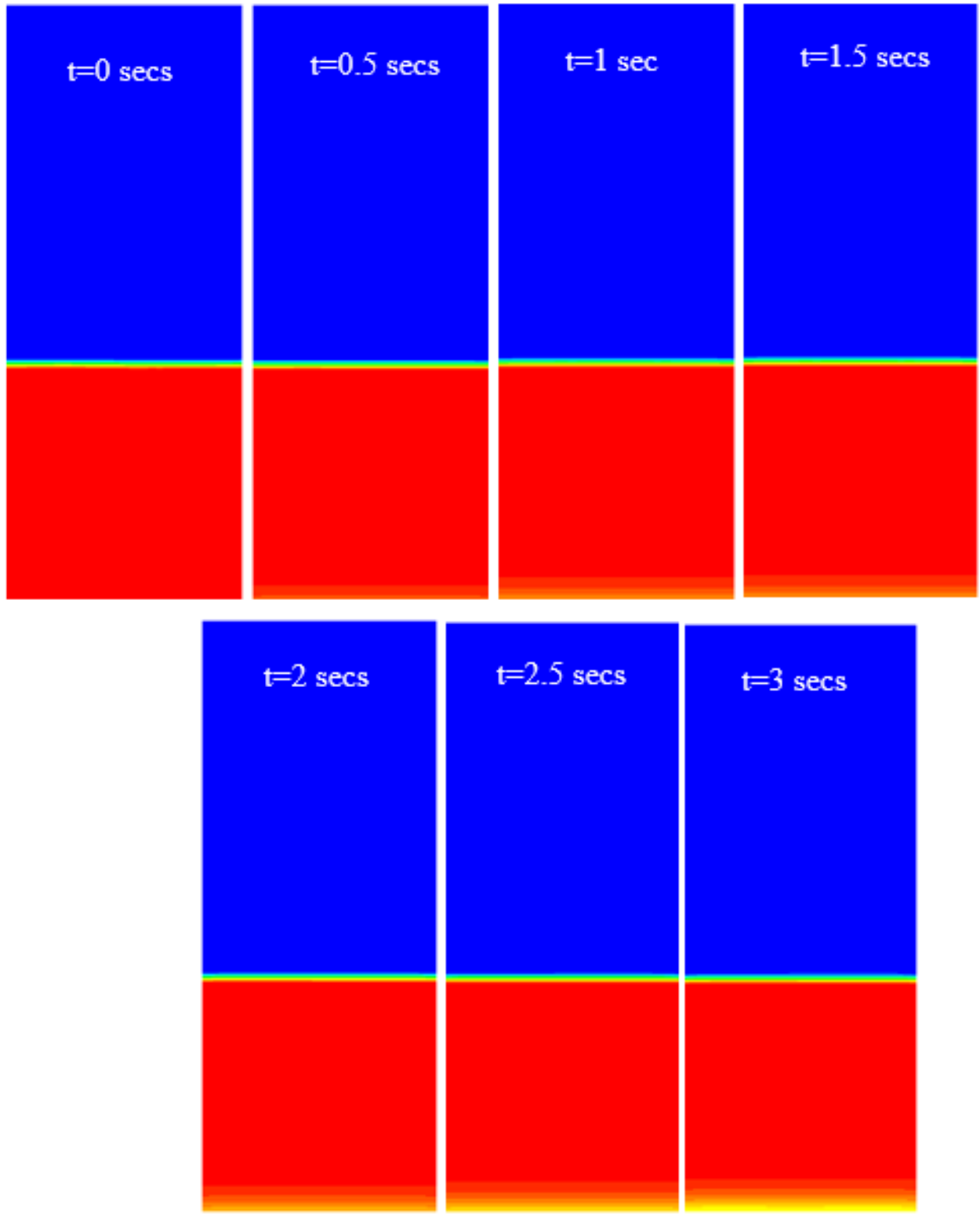

Figure 17. $\mathrm{SO}_{3}$ liquid volume fraction (no surface tension) 


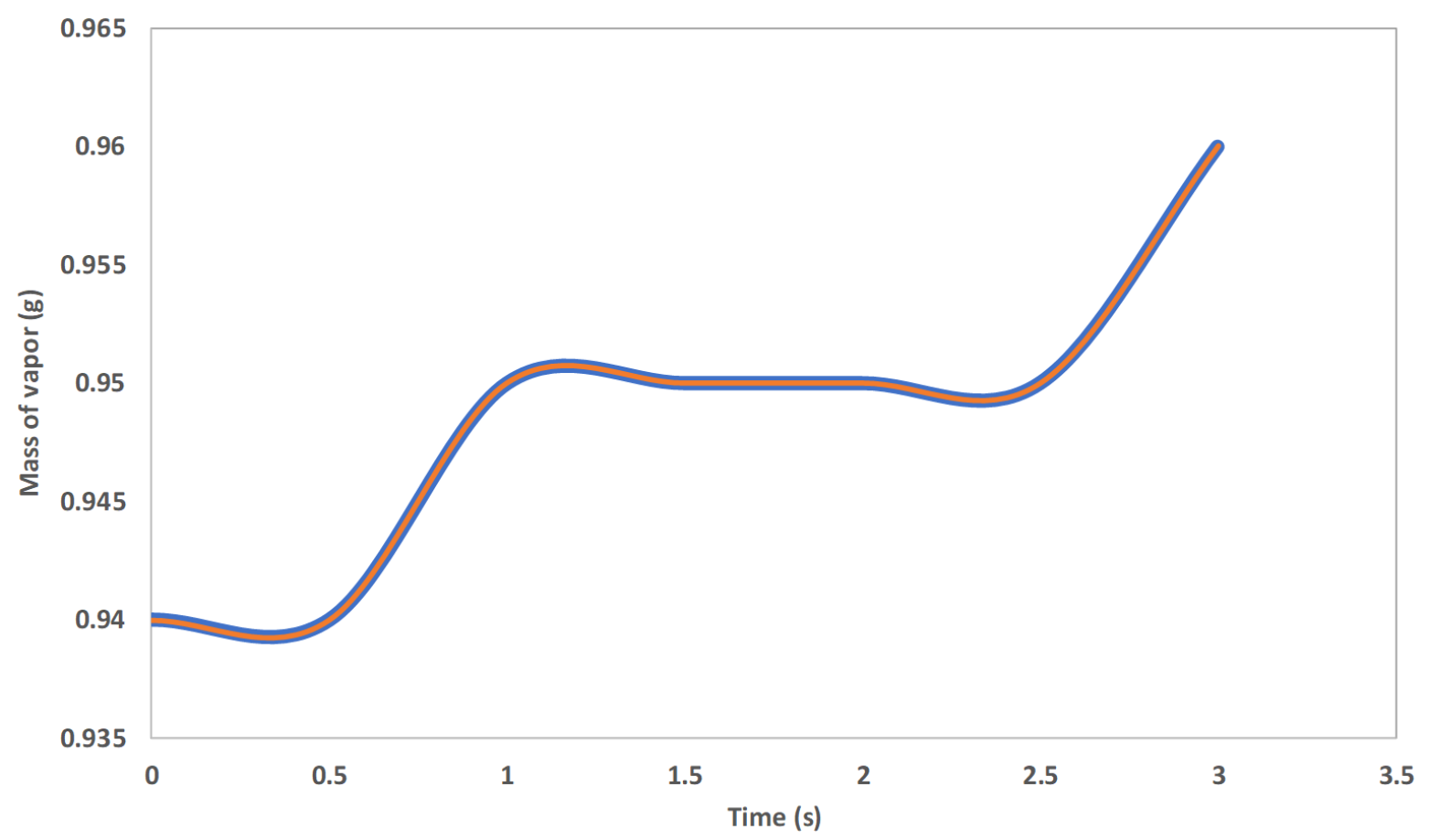

Without surface tension $\quad$ With surface tension

Figure 18. Effect of surface tension on mass of vapor

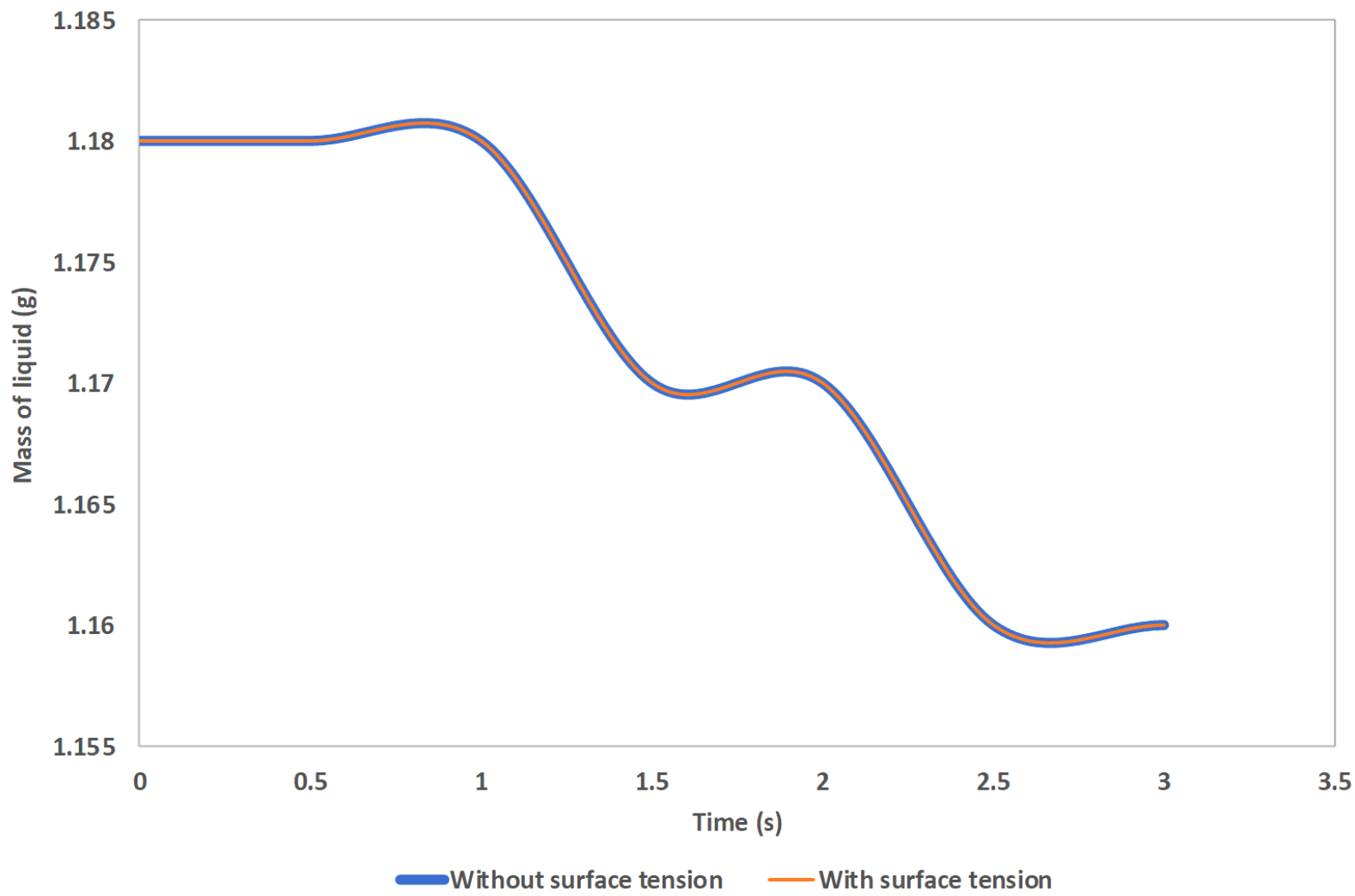

Figure 19. Effect of surface tension on liquid vaporization 


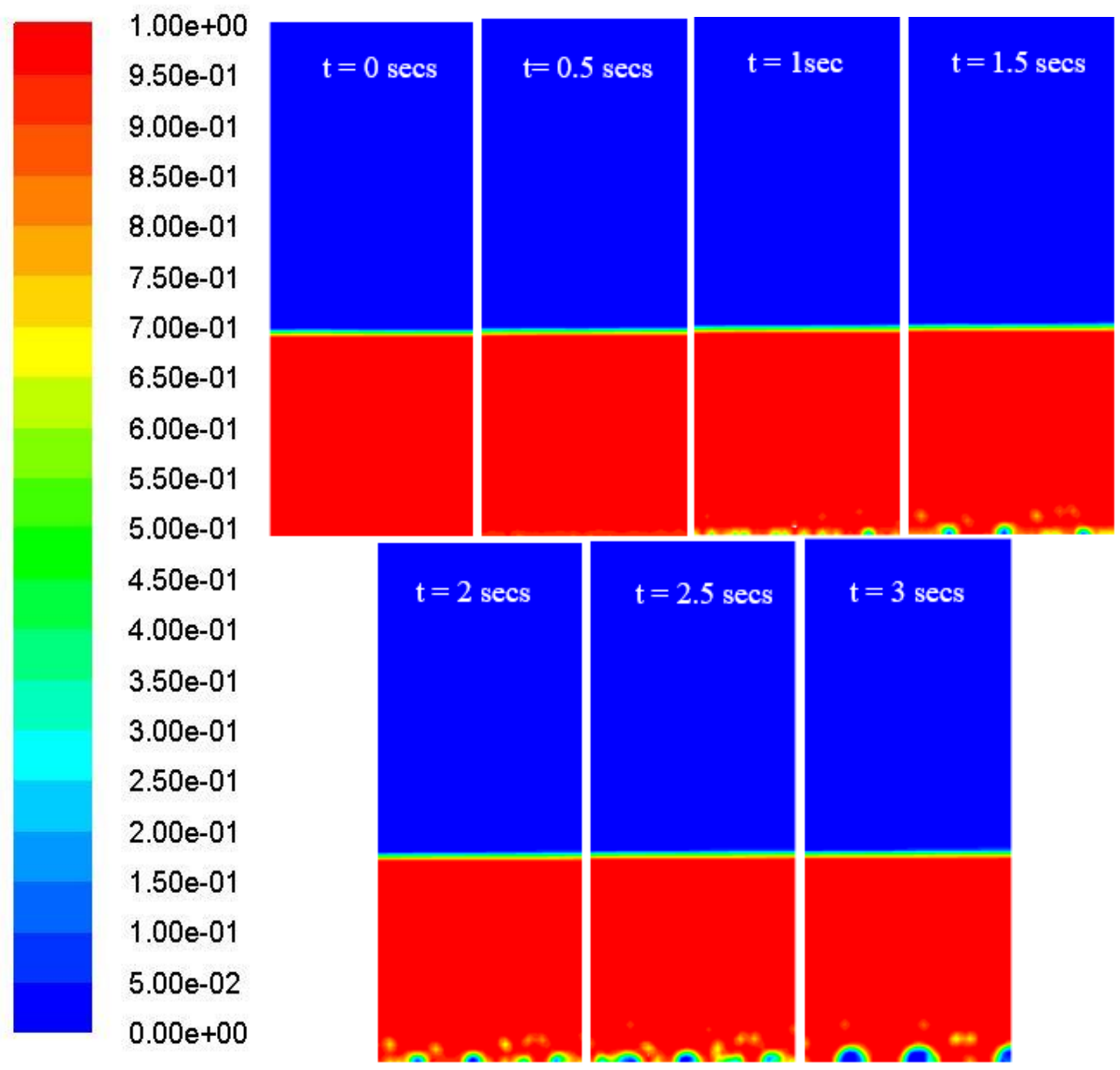

Figure 20. Liquid $\mathrm{SO}_{3}$ volume fraction $(0.001 \mathrm{~N} / \mathrm{m}$ surface tension $)$

The vaporization rate of both the models were similar since the simulation was run for a little amount of time. However, it was found from figures 17 and 20 that surface tension makes a difference. More, figures 18 and 19 show that the rate of liquid decline and vaporization were same for both models, which was probably due to small run time, too.

\subsection{Heat transfer results}

The next model simulated the addition of a heating mantel around the reactor. The output was the time taken by the heating mantel to raise the reactor content temperature to $488 \mathrm{~K}$. A heat flux of $10 \mathrm{~kW} / \mathrm{m}^{2}$ (equivalent to $145 \mathrm{~W}$ heat transfer rate) was applied around the reactor walls, which was based on a heating coil specification of $6 \mathrm{~W} / \mathrm{in}^{2}$ [25]. The heating mantel needed 10 minutes 
to raise the temperature inside the reactor to $324 \mathrm{~K}$. Figure 21 shows the temperature profile at the reactor positions shown in Figure 10. Figure 21 shows almost linear increase of temperature with time. Considering a constant heat transfer profile, it was estimated that time required to reach 488 $\mathrm{K}$ was 39 min.

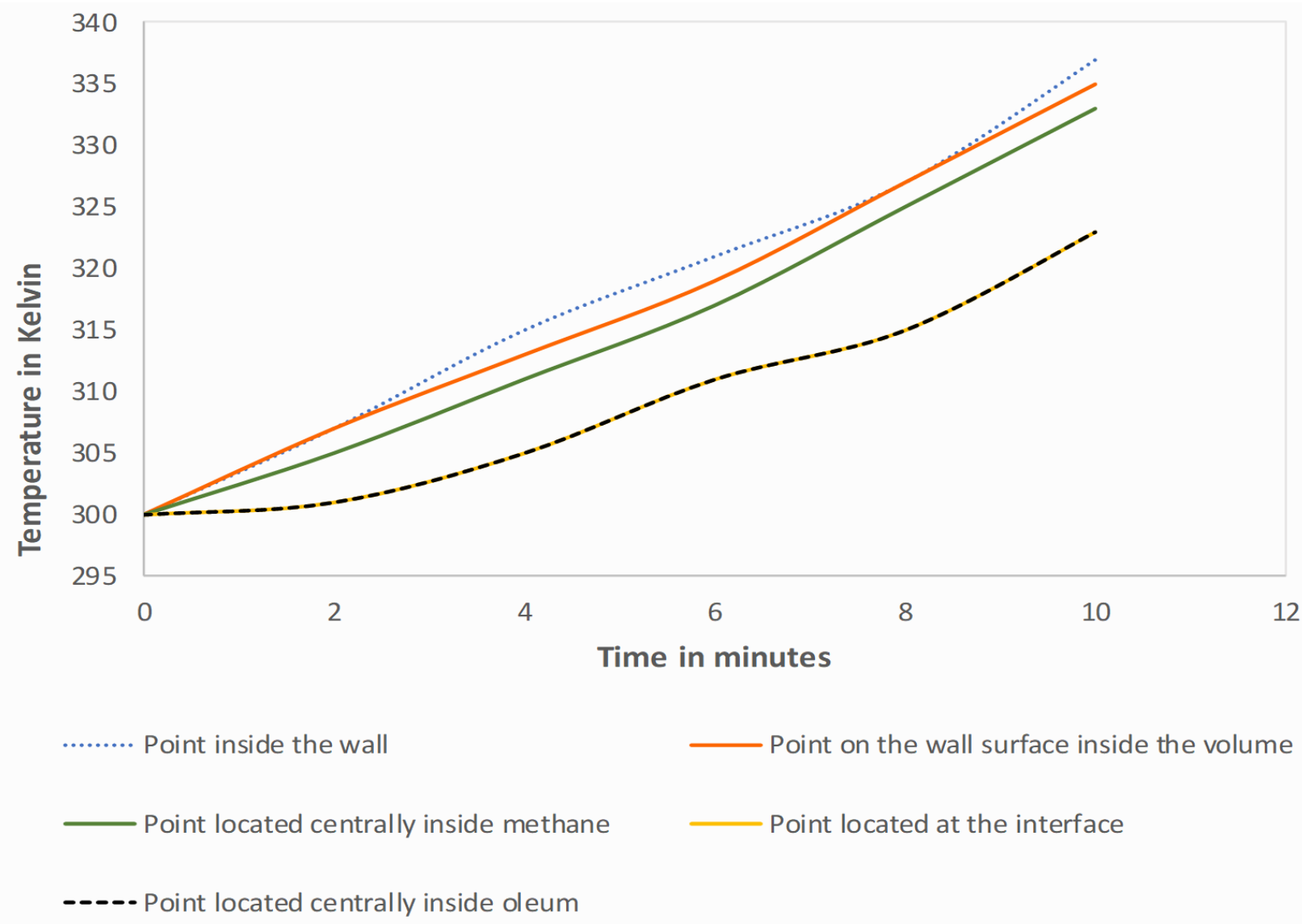

Figure 21. Temperature profile at various points in the reactor

Figure 22 show the static temperature contours across the reactor at several time instances $(0$, 2, 4, 8, and $10 \mathrm{~min})$. The results were comparable with the experimental data after 25 minutes. Initially, at $t=0 \mathrm{~min}$, the contents of the reactor were at $300 \mathrm{~K}$. After 2 minutes, the wall temperature and reactor content temperatures increase in average by 7 and 4 degrees, respectively. 

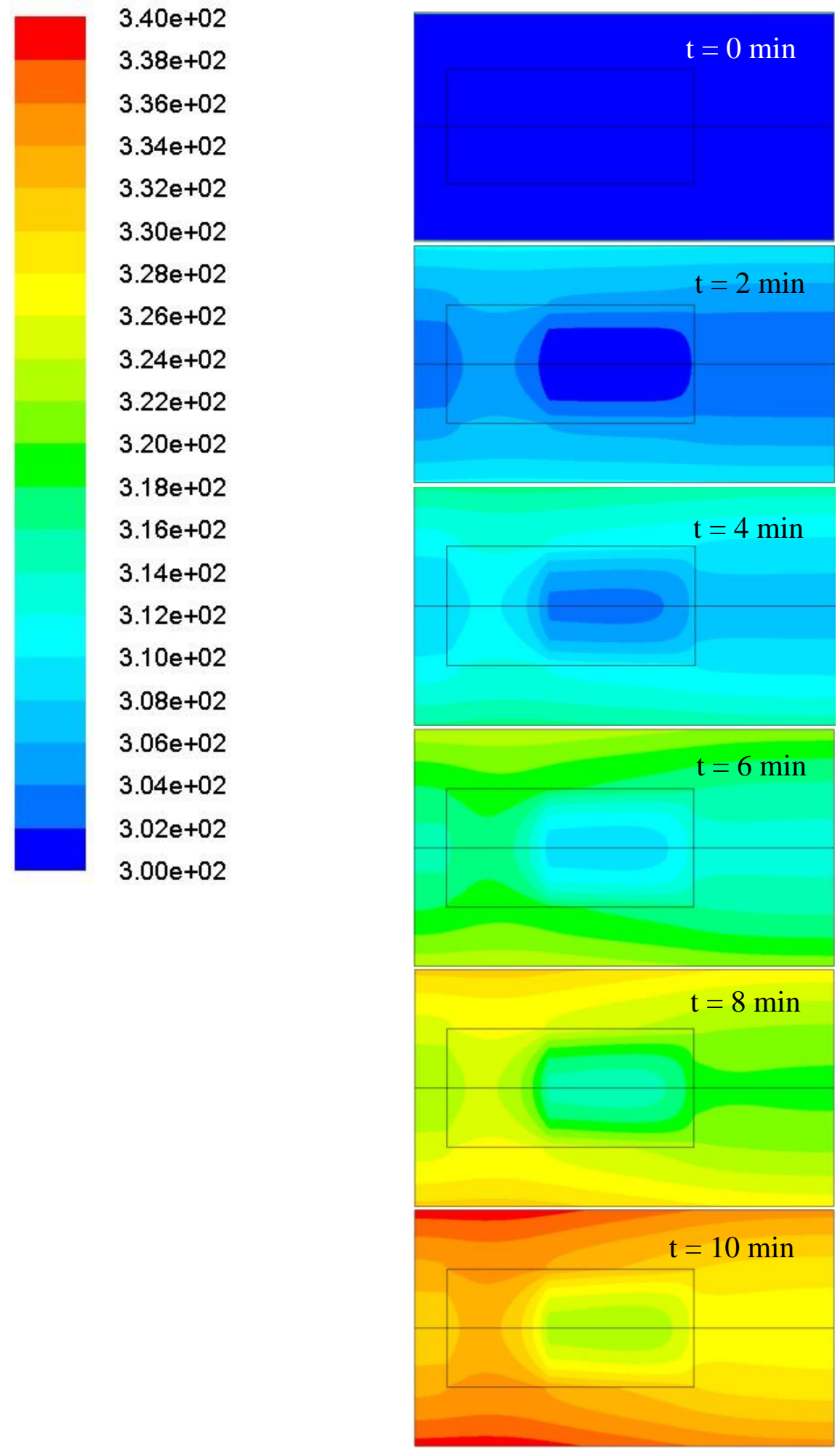

Figure. 22 Inside reactor temperature function of time 


\section{Chapter 4. Conclusions and future work}

This project investigated thermal processes inside a laboratory rector build for methane-tomethanol synthesis. Several heat transfer models with or without phase change were built to investigate the various thermal phenomena.

The water vaporization model provided an overview of how well a relatively-simple CFD simulation can predict vaporization rates, compared to both experimental and thermodynamical models. The main conclusions of this study were:

- The simulation simulated the vaporization of liquid, but it did not conserve reactor mass This suggests that the default VOF approach is not capable of heat and mass transfer through the phase interface [26]. A user-defined function (UDF) is probably needed to solve this issue.

- The timestep did make a difference on the results. A smaller timestep increased vaporization.

- In the sulfur trioxide model, the effects of using surface tension were observed in the contours but there was no difference in the vaporization rates, most probably due to small simulation run time.

- The reactor heating model showed no vaporization, since the simulation did not reach the boiling point of oleum (386K [27])

- More heat transfer from the bottom side of the reactor compared to the sides is needed because of the thicker bottom and oleum being at the bottom of the reactor (left side in the heat transfer simulation).

It is not recommended to place a heater just at the bottom side. The optimum heater design would use both sides and bottom heaters, which would result in a more uniform heat input. Specifically, the best design would use three different heating units placed around the lateral walls of the reactor, with individual heat controls. This way, the heat flux to the reactor and interior reactor temperature can be properly controlled. An additional cooling coil can be incorporated to remove the heat produced during the synthesis process.

The main suggestions for future work are:

- For water vaporization, the simulation values can be validated by writing a UDF and changing mesh size or vaporization frequency. By performing various combinations of 
mesh size and vaporization frequency with the UDF, the simulation values can be correlated with the ones in the experiment. The thermodynamic model can then be used for further sanity.

- In the heat transfer model, a zone-based heat flux boundary can be used for better simulation results.

- Using the temp profile from the heating model the vaporization of oleum can be simulated.

- The heat transfer depended on reactor walls and content properties. Greater homogeneity increases uniform heat transfer. A paddle is generally installed to make sure the contents of the reactor volume have a near homogenous state. However, one must ensure that the speed of paddle do not negatively affect the reactor performance.

- Chemkin can be implemented in the simulation once conversion rates are determined to properly simulate the heat of reaction at various reaction steps.

Figure 23 shows a model of the reactor that includes a stirrer for homogeneous mixing. The model was built in Solidworks and Ansys ${ }^{\circledR}$ Design Modeler. The dimensions of the model were comparable to the one used in the experiment. Relative motion was applied to the stirrer with respect to the reactor wall. The mixing was simulated for $10 \mathrm{~s}$ using 10,000-time steps. The stirrer was rotating at $500 \mathrm{rpm}$. The outlet and inlet for the reactor were open to the atmosphere and air was the working fluid. Figure 23 shows the simulation results at $t=0.1 \mathrm{~s}$ and at $t=0.8 \mathrm{~s}$. 


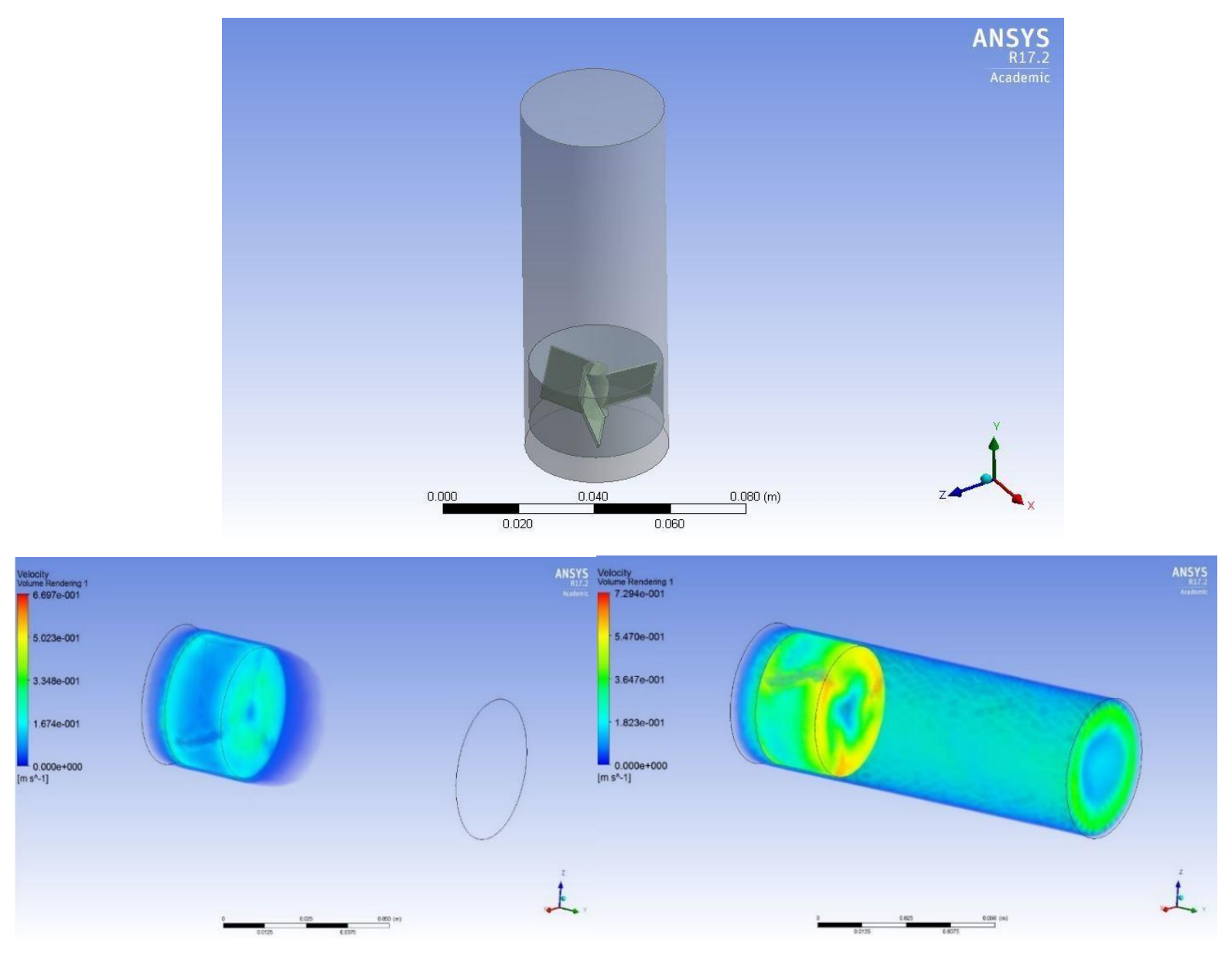

Figure 23. Reactor model with stirrer. Top - the Solidworks model. Bottom: simulation at $t=0.1$ $\mathrm{s}$ and at $t=0.8 \mathrm{~s}$, for a stirrer speed of 500rpm. 


\section{References}

[1] Aslam, M. U., Masjuki, H. H., Kalam, M. A., Abdesselam, H., Mahlia, T. M. I., and Amalina, M. A., "An experimental investigation of $\mathrm{CNG}$ as an alternative fuel for a retrofitted gasoline vehicle," Fuel, Vol. 85 No. 5-6 (2006): pp. 717-724, DOI: 10.1016/j.fuel.2005.09.004

[2] Khan, M.I., Yasmeen, T., and Shakoor, A., "Technical overview of compressed natural gas (CNG) as a transportation fuel," Renewable and Sustainable Energy Reviews, Vol. 51 (2015): Pp. 785-797. DOI : 10.1016/j.rser.2015.06.053

[3] DeLuchi, M. A., Johnston, R. A., and Sperling, D., "Methanol vs. Natural Gas Vehicles: A Comparison of Resource Supply, Performance, Emissions, Fuel Storage, Safety, Costs, and Transitions", Journal of Fuels and Lubricants, Vol. 97 Section 3 (1988): pp. 921-962

[4] Pourkhesalian, A. M., Shamekhi, A. H., and Salimi, F., "Performance and Emission Comparison and Investigation of Alternative Fuels in SI Engines," SAE Technical Paper 2016-010882 (2016)

[5] Urbanski, T., "Chemistry and Technology of Explosives”, Pergamon Press, Oxford, 1965, Vol 2, pp 329.

[6] Pubchem open chemistry database, https://pubchem.ncbi.nlm.nih.gov/compound/oleum, [Accessed: 24 - Apr - 2018]

[7]Lunsford, J. H., "Catalytic conversion of methane to more useful chemicals and fuels: a challenge for the 21st century," Catalysis Today Vol. 63 Issue. 2-4 (2004): pp. 165-174

[8]Baerns, M., Ross, J. R. H., "Perspectives in Catalysis" (Ed.: Thomas J A, Zamaraev K I), Blackwell Oxford (1992)

[9] Marco, M., "Introduction to Chemical Engineering: Chemical Reaction Engineering", ETH Swiss Federal Institute of Technology Zurich (2015)

[10] Muttaliba, N. A. A., Zaidel, D. N. A., Alam, M. N. H. Z., "Effect of Impeller Design on the Rate of Reaction of Hydrolysis in Batch Reactor," The Italian Association of Chemical Engineering, Fuel, Vol. 56 (2017)

[11] James G. Speight, J. G., "Handbook of Petroleum Refining”, CRC press, (2016)

[12] Palkovits R, Antonietti M, Kuhn P, Thomas A, and Schth F, "Solid Catalysts for the Selective Low-Temperature Oxidation of Methane to Methanol." Angewandte Chemie, Vol. 48, Issue. 37 (2009): pp 6909-6912. DOI: 10.1002/anie.200902009 
[13] Hirt, C. W., and Nichols, B. D., "Volume of Fluid (VOF) Method for the Dynamics of Free Boundary," Journal of Computational Physics. Vol. 39 (1981), pp. 201-225.

[14] Youngs, D. L., “Time-Dependent Multi-Material Flow with Large Fluid Distortion”, pp. 273-285, Academic Press, New York (1982).

[15] Welch, S. W. J., and Wilson, J., A., "Volume of Fluid Based Method for Fluid Flows with Phase Change”, Journal of Computational Physics, vol. 160, pp. 662-682 (2000).

[16] Akhtar, M. W., and Kleis, S. J., "Boiling Flow Simulations on Adaptive Octree Grids," Int. J. Multiphase Flow, vol. 53, pp. 88-9, (2013).

[17] Jeon, S. S., Kim, S. J., and Park, G. C., "Numerical Study of Condensing Bubble in Subcooled Boiling Flow Using Volume of Fluid Model," Chem. Eng. Sci., vol. 66, pp. 5899- 5909 (2011).

[18] Pan, L. M., Tan, Z. W., Chen, D. Q., and Xue, L. C., "Numerical Investigation of Vapor

Bubble Condensation Characteristics of Subcooled Flow Boiling in Vertical Rectangular Channel," Nuclear Eng. Des., vol. 248, pp. 126-136 (2012).

[19] Ganapathy, H., Shooshtari, A., Choo, K., Dessiatoun, S., Alshehhi, M., and Ohadi, M., "Volume of Fluid-based Numerical Modeling of Condensation Heat Transfer and Fluid Flow Characteristics in Microchannels," Int. J. Heat Mass Transfer, vol. 65, pp. 62-72 (2013).

[20] Lee, W. H., “A Pressure Iteration Scheme for Two-Phase Flow Modeling," Multiphase Transport Fundamentals, Reactor Safety, Applications, Hemisphere, Washington, DC (1980).

[21] Wu, H. L., Peng, X. F., Ye, P., and Eric Gong, Y., "Simulation of Refrigerant Flow Boiling in Serpentine Tubes,” Int. J. Heat Mass Transfer, vol. 50, pp. 1186-1195 (2007).

[22] ANSYS® Academic Research Mechanical, 11.0

[23] Considine, Douglas, M., "Chemical and Process Technology Encyclopedia”, McGraw-Hill (1974), pp 1070-1.

[24] Gamut Supply LLC, https://www.gamut.com/p/heating-tape-with-adjustable-thermostatcontrol-controllerincluded-NTA0NDY0 [Accessed: 24 - Apr - 2018]

[25] Huang, M., Wu, L. L., and Chen, B., "A Piecewise Linear Interface-Capturing Volume of Fluid Method Based on Unstructured Grids," Numerical Heat Transfer B, vol. 61, pp. 412-437 (2012).

[26] Sun, D., Xu, J., and Chen, Q., “ Modeling of the evaporation and condensation phasechange problems," Numerical Heat Transfer, Part B, No. 66 pp.326-342 (2014) 
[27] INCHEM, Chemical Safety Information from Intergovernmental Organizations, http://www.inchem.org/documents/icsc/icsc/eics1447.html [Accessed: 24 - Apr - 2018] 


\section{Appendix}

\section{The Appendix presents the MATLAB $®$ code for the thermodynamic model discussed in}

\section{Chapter 3.}

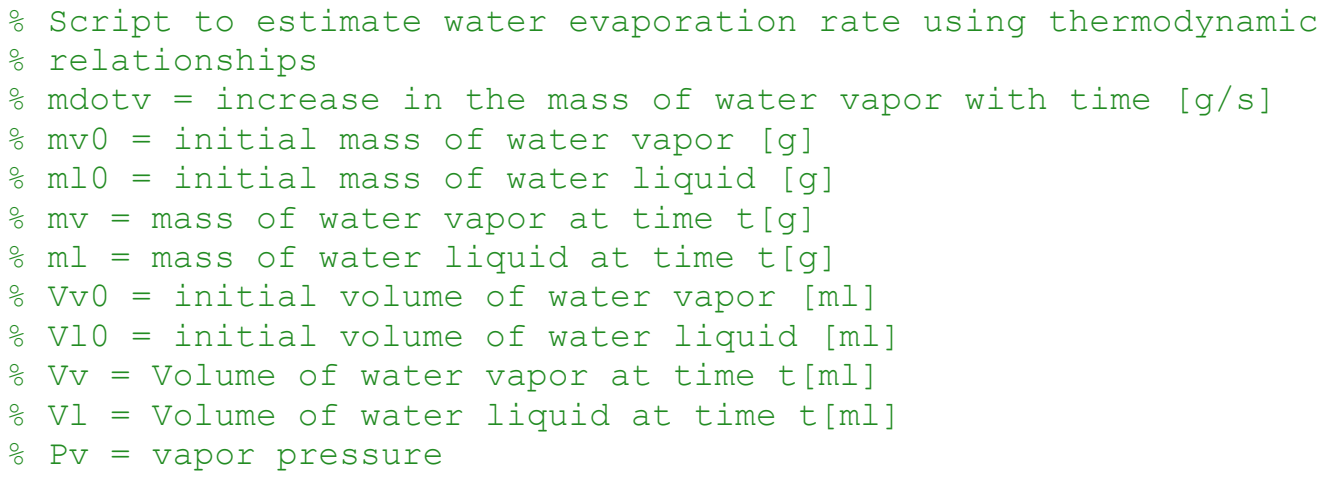


end

figure; $p l o t(t, V v, t, V l, t,(V l+V v)$ )

figure; plot ( $t, m v, t, m l, t,(m l+m v)$ )

figure; plot ( $t, \mathrm{Pv})$

figure; plot (t (1:688), mv(1:688)) 